\title{
THE USE OF BODY-WAVE SPECTRA IN THE DETERMINATION OF SEISMIC-SOURCE PARAMETERS
}

\author{
By Thomas C. Hanks and Max Wyss
}

\section{ABSTRACT}

Teleseismic determinations of body-wave $(P, S)$ spectra, interpreted in terms of the Brune (1970) seismic-source model, are used to estimate the parameters seismic moment $\left(M_{o}\right)$ and source dimension $(r)$ for three large, shallow, strike-slip earthquakes occurring on nearly vertical fault planes and for which the same parameters can be determined from field $(F)$ data. These earthquakes are (1) the Borrego Mountain, California, earthquake (April 9, 1968) for which $\left[\vec{M}_{o}(P)=10, \bar{M}_{o}(S)=6.6\right.$, and $\left.M_{o}(F)=3.6\right] \times 10^{25}$ dyne-cm and $[\vec{r}(P)=$ $14, \bar{r}(S)=23$, and $L / 2(F)=17] \mathrm{km}$; (2) the Mudurnu Valley, Turkey, earthquake (July 22, 1967) for which $\left[\bar{M}_{o}(P)=9.1, \bar{M}_{o}(S)=8.5\right.$, and $M_{o}(F)=$ $7.4] \times 10^{26}$ dyne-cm, and $[\vec{r}(P)=39, \bar{r}(S)=48$, and $L / 2(F)=40] \mathrm{km}$; and (3) the Dasht-e-Bayāz, Iran, earthquake (August 31, 1968) for which $\left[\bar{M}_{o}(P)=\right.$ 4.8, $\bar{M}_{0}(S)=8.6$, and $M_{0}(F)=18 \mid \times 10^{26}$ dyne-cm, and $[\bar{r}(P)=S 1, \bar{r}(S)=48$, and $L / 2(F)=40] \mathrm{km}$. The Brune (1970) model is well-calibrated with respect to the determination of these parameters for the earthquakes considered. A minimum estimate for the radiated energy can be expressed in terms of $M_{o}$ and $r$; this estimate is low by a factor of 10 with respect to the estimate obtained from energy-magnitude relations for these three earthquakes. The stress drops of these events are of the order of $\mathbf{1 0}$ bars.

\section{INTRODUCTION}

In this paper, we will use body-wave spectra to determine both the source dimension and seismic moment for three earthquakes for which these same parameters can be determined from field observations. These events are the Borrego Mountain, California, earthquake $\left(M_{L}=6.4\right)$, the Mudurnu Valley, Turkey, earthquake $(M=7.1)$ and the Dasht-e-Bayāz, Iran, earthquake $(M=7.2)$. These three earthquakes generated predominantly strike-slip motion on a nearly vertical fault plane; all produced well-defined surface ruptures and measurable offsets across the fault surface.

A general feature of theoretical, far-field displacement spectra $\Omega(\omega)$ generated by a spatially stationary seismic or explosive source is the corner (or peak) frequency $f_{0}$ ( $\omega$ is circular frequency and $f=\omega / 2 \pi$ is frequency in $\mathrm{Hz}$ ), which can be related to the source dimension through the equation

$$
f_{o}=(c v / r) \text {. }
$$

Here $v$ is the elastic wave velocity of the body phase in the vicinity of the source, and $r$ is the source dimension; $c$ is a constant of order 1 and depends on the particular source model. An equation of the form of (1) holds whether the model be an explosion (Sharpe, 1942; Kasahara, 1957), a shear dislocation (Jeffreys, 1931; Haskell, 1964; Aki, 1967: Brune, 1970), or a stress relaxation source (Archambeau, 1964, 1968).

Kasahara (1957) utilized this result and spectral data obtained from $P$ waves to determine source dimensions for deep and shallow Japanese earthquakes. Berckhemer and Jacob (1968), with a variation of (1) involving the rupture velocity of a propagating source, estimated source dimensions and stress drops for some deep South American 
earthquakes. Wyss et al. (1971) used spectral information in the frequency band $0.03<f<2 \mathrm{~Hz}$ to demonstrate that three nuclear explosions had source dimensions almost an order of magnitude less than four earthquakes of comparable magnitude $m_{b}$.

For frequencies higher than $f_{o}, \Omega(\omega)$ reflects the short time behavior of the source displacement function; for $f \gg f_{o}$, the spectral amplitudes must decay at least as fast as $f^{-\gamma}, \gamma>1.5$, so that the energy integral is bounded. An important aspect of the Brune (1970) model of shear-wave spectra is that $\Omega(\omega)$ falls off only as $f^{-1}$ in the range $f_{o}<f<$ $f_{o} / \varepsilon$ where $\varepsilon$ is the fractional stress drop

$$
\varepsilon=\left(\Delta \sigma / \sigma_{\mathrm{eff}}\right)
$$

Here $\Delta \sigma$ is the stress drop and $\sigma_{\text {eff }}$ is the effective stress (prestress minus frictional stress opposing motion on the fault surface).

An equally important result follows from the dislocation model of a seismic source: for $f \ll f_{o}, \Omega(\omega)$ assumes a constant value that can be related to the seismic moment $M_{o}$ (either of the moments associated with the double-couple representation of the seismic source (Keilis-Borok, 1960)). Aki (1966) demonstrated that the seismic moment can also be obtained directly from field $(F)$ observations

$$
M_{o}(F)=\mu A \bar{u}
$$

where $\mu$ is the shear modulus, $A$ is the area of the fault surface, and $\bar{u}$ is the average displacement across the fault surface. The seismic moment determination obtained from the spectra of radiated waves has not been systematically compared to field observations because reliable long-period azimuth coverage has only been available since the installation of the WWSSN system in 1963 and because large earthquakes often occur in regions inaccessible to field measurements.

Seismic moments are generally obtained from spectra derived from well-dispersed surface waves, following a procedure similar to that of Ben-Menahem and Harkrider (1964). The preference for surface-wave spectra is that, for large shallow earthquakes, spectral information at periods in the range of several hundred seconds can readily be obtained; for body phases, the long-period spectral data will be contaminated by multiple arrivals that follow within 60 to $100 \mathrm{sec}$, except at very restricted ranges of depths and epicentral distances. On the other hand, the smaller and deeper earthquakes, generate significantly smaller surface waves, and the use of body-wave spectra in the moment determinations for these events is preferable.

Again with the exception of the larger shallow earthquakes, body-wave spectra are also preferable for the determination of the source dimension, since $f_{o}$ is generally in a period range at which surface-wave amplitudes are a sensitive function of the propagation path. The intent of this paper is to demonstrate that both the source dimension and seismic moment can be reliably, and relatively easily, obtained from the interpretation of the body-wave spectra in terms of Brune's (1970) seismic-source model. This "calibration check" provides justification for its use in current studies of source parameter determinations for which there is no field evidence available.

\section{Determination and INTERPRETATION OF BODy-Wave SPECTRA}

Summary of theoretical results. Before presenting our method to determine the source spectrum from a teleseismically-observed body phase, we will summarize the theoretical relations with which the spectrum will be interpreted. In a later section, we will return to both the theoretical and observational limitations associated with their use. Figure 1 gives the far-field displacement spectra following Brune (1970). The $S$-wave spectrum 
is for the case of complete effective stress drop. The seismic moment $M_{0}(S)$ is determined from the $S$-wave spectrum through the relation

$$
M_{o}(S)=\frac{\Omega_{o}(S)}{\mathscr{R}_{\theta \varphi}(S)} 4 \pi \rho R \beta^{3} \quad \text { (Keilis-Borok, 1960) }
$$

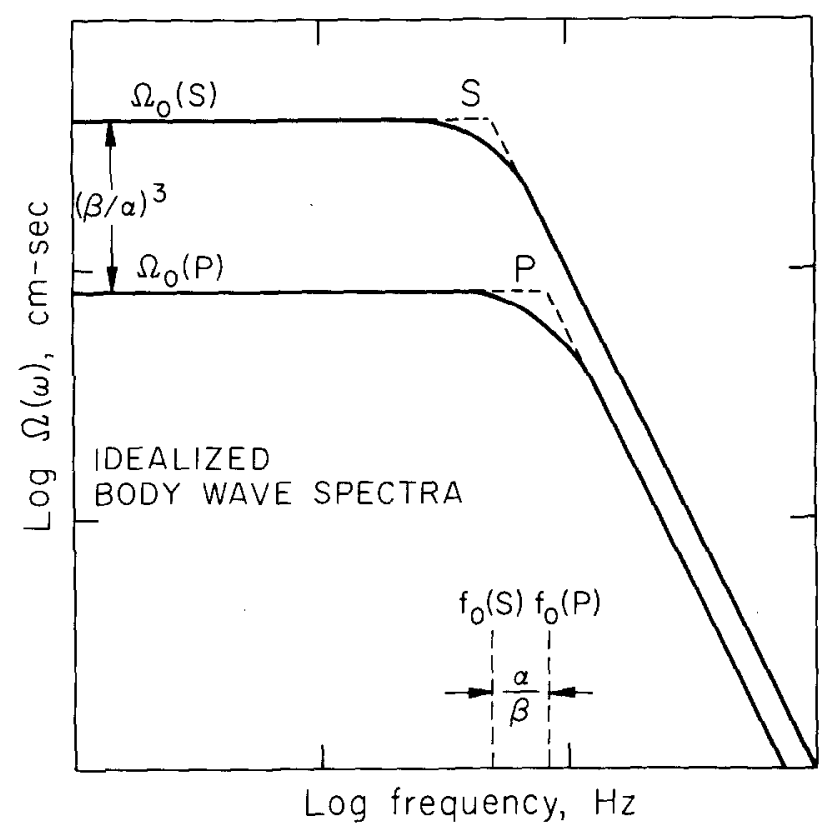

Fici. I. Idealized body-wave spectra corrected for all propagation effects. $S$-wave spectrum from Brune (1970) for the case $\varepsilon=1$. $P$-wave spectrum after discussion in text.

where

$M_{o}(S)=$ seismic moment determined by the $S$-wave spectrum

$\Omega_{o}(S)=$ long-period spectral level of the $S$ wave

$\mathscr{R}_{\theta \varphi}(S)=$ radiation pattern for the $S$ wave

$\rho \quad=$ density $=2.7 \mathrm{gm} / \mathrm{cm}^{3}$

$R \quad=$ accounts for spreading in a layered, spherical earth

$\beta \quad=$ shear-wave velocity $=3.5 \mathrm{~km} / \mathrm{sec}$.

The source dimension is given by

where

$$
r(S)=\frac{2.34 \beta}{2 \pi f_{o}(S)} \quad \begin{aligned}
& \text { [corrected from Brune }(1970) \\
& \text { by Brune }(1971)]
\end{aligned}
$$

$r(S)=$ radius of a circular source area determined by the $S$-wave spectrum $f_{o}(S)=$ corner (peak) frequency of the $S$-wave spectrum.

Although Brune (1970) does not attempt to relate the source dimension to a theoretical $P$-wave spectrum, it nevertheless seems reasonable that this paramcter can be recovered from the $P$-wave radiation. For several reasons, $P$ waves are preferable to $S$ waves for spectral analysis, and we will estimate $M_{o}$ and $r$ from the $P$-wave spectrum as well. For the $P$-wave spectra, we use

$$
M_{o}(P)=\frac{\Omega_{o}(P)}{\mathscr{R}_{\theta \varphi}(P)} 4 \pi \rho R \alpha^{3}
$$


where

$M_{\mathrm{o}}(P)=$ seismic moment determined by the $P$-wave spectrum

$\Omega_{o}(P)=$ long-period spectral level of the $P$ wave

$\mathscr{R}_{\theta \varphi}(P)=$ radiation pattern for the $P$ wave

$\alpha \quad=P$-wave velocity $=6.0 \mathrm{~km} / \mathrm{sec}$

and

where

$$
r(P)=\frac{2.34 \alpha}{2 \pi f_{o}(P)}
$$

$r(P)=$ radius of a circular source area determined by the $P$-wave spectrum

$f_{o}(P)=$ corner (peak) frequency of the $P$-wave spectrum.

The justification for (7) is that the corner frequency is defined by the interference of radiated waves with wavelengths greater than a critical value $\lambda_{o}=0(r)$. To preserve the $\lambda_{o}$ criterion, $f_{o}(P)$ should then be shifted by a factor of $\alpha / \beta$ relative to $f_{o}(S)$ (Figure 1 ). In that the rationale for (7) is largely intuitive, we will consider its validity as a matter to be decided empirically.

The basic theme of this paper involves a comparison of $M_{o}(P), M_{o}(S)$, and $M_{o}(F)$ as well as an assessment of the accuracy with which they can be determined, and, similarly, for $r(P), r(S)$, and $L / 2(F)$. With respect to the latter comparison, we have assumed that the diameter of a circular fault area should be equal to the observed fault length

$$
L / 2(F)=r(P, S) \text {. }
$$

In fact, the areas of the fault planes to be considered here are probably more nearly rectangular, characterized by a fault length $L$ and a width (depth) $h$. In order that (8) be a meaningful comparison, it is necessary to rescale the Brune (1970) spectra when $A=L \cdot h$. To do so, we will derive an equivalent form of $(5)$, the derived quantity (the source dimension) being $L / 2$.

The Brune (1970) spectra are scaled to conserve energy at high frequencies and to match the Keilis-Borok (1960) moment at low frequencies. Let

$$
A=L \cdot h=2(L / 2) \delta \cdot L / 2, \delta=h /(L / 2) .
$$

Then, using B23, B24, and B25 [Brune, 1970, equations $(23,24,25)]$, with $L / 2$ replacing $r$, B26 becomes

$$
f \simeq \sqrt{2 \delta / \pi}
$$

taking the quantity $(S / 0.8)^{\frac{1}{2}} \simeq 1$. The notation $f$ and $S$ used immediately above follows Brune (1970); $f$ is a scalar constant associated with geometrical spreading, and $S$ is a factor correcting for conversion of $S$ waves to $P$ waves. With the neglect of end effects, Brune's (1970) equation (30) becomes

$$
\bar{u}_{d}=\frac{3}{4} u_{d}^{\max }=1.5 \sigma h / \mu .
$$

The quantity $u_{d}{ }^{\max }$ is the final dislocation for 100 per cent stress drop. Then Brune's (1970) equation (31) becomes

and the equation

$$
M_{o}^{100}=1.5 \sigma L h^{2}
$$

$$
3 \mathscr{R}_{\theta \varphi} \sigma(L / 2)^{3} \delta^{2} / 4 \pi \rho R \beta^{3}=\mathscr{R}_{\theta \varphi} \sigma \beta f(L / 2) / \mu R v^{2}
$$

follows as in Brune (1970) and determines $v^{2}$ in terms of $L / 2$. Here $v$ is the nondimensional corner frequency of Brune (1970) for the case $\varepsilon=1 ; v=2 \pi f_{0}$. The result is

$$
v=1.82 \beta / \delta^{\frac{3}{4}}(L / 2)
$$


When $1.82 / \delta^{3}=2.34, L / 2 \equiv r$, and the choice of $2 r=L$ to compare with the field observations is appropriate. Table 1 lists the quantity $1.82 / \delta^{\frac{3}{4}}$ for several values of $\delta$.

The three earthquakes to be considered have $\delta$ ratios between 0.71 and 0.50 . From Table 1 , we see that the $L / 2$ determinations from (14) for these earthquakes will be a factor of 1 to 1.3 greater than the $r$ determination from (5). An error of perhaps a factor of 1.5 is associated with the determination of $v$ from the spectral data (see below), so we do not anticipate a large error in using (5) to compare with $L / 2$. We will postpone further discussion of this point until the source dimensions have been obtained from the body-wave spectra and compared to the field observations.

TABLE 1

Scaling of $v$ to a Rectangular Fault as a Function

of $h /(L / 2)$

\begin{tabular}{lc}
\hline$\delta=h /(L / 2)$ & $1.82 / \delta^{\frac{3}{4}}$ \\
\hline 1.00 & 1.82 \\
0.75 & 2.25 \\
0.50 & 3.05 \\
0.20 & 6.07 \\
\hline
\end{tabular}

Determination of body-wave spectra. The body-wave spectra presented in this work have been obtained from WWSSN stations. Both short- and long-period $P$ - and $S$-wave signals have been utilized to obtain as much spectral information for a particular phase as possible. The body-wave spectra $\Omega(\omega)$ are determined from an evaluation from

$$
\left|\int_{0}^{T_{0}} g(t) e^{-i \omega t} d t\right|
$$

where $g(t)$ is the digitized body phase, the integral is evaluated numerically, and the body-wave spectrum is the modulus of the resulting complex sum. The infinite Fourier transform is reduced to (15) by assuming that $g(t) \equiv 0$ for $t<0$ and $t>T_{o}, T_{o}$ being the sample length. The resulting spectral amplitudes are then corrected for the instrument response to obtain displacement spectral amplitudes.

We emphasize here that we have interpreted the spectral data in terms of Figure 1, that is, a constant long-period level $\Omega_{o}$, corner frequency $f_{o}$, and high-frequency decay of $f^{-\gamma}, \gamma=2$, except when the short-period spectral data prohibit the last assumption $(\gamma \neq 2)$. A spectral peak, such as arises in the stress relaxation model of Archambeau (1964, 1968), cannot be excluded on the basis of the limited frequency information available $(f \geqq 0.01 \mathrm{~Hz})$. Generally, the body-wave spectra admit an interpretation of a flat long-period level with some indication of a peaked spectrum. In any case, the primary interest here is to determine whether the moment calculated on the basis of such an interpretation, together with (4) or (6), has any relationship to the moment determined from the field data.

Figure 2 demonstrates how the long-period spectrum varies as a function of the sample length. Various sample lengths of both the $P$ and $S$ wave of the Turkey event at station HKC have been considered; the resulting spectra have been corrected for the instrument response and seismic attenuation following Julian and Anderson (1968). The upper sequence of diagrams in Figure 2 is for the $P$ wave; spectrum (3) is considered to be the "best" and the short-period $P$ data are also included here. The interpreted long-period level $\Omega_{o}(P)$ of (3) is indicated on the other three $P$-wave spectra, the high-frequency terminus of this line representing $f_{0}(P)$. The long-period level can be estimated to a factor of 2 from any of the four spectra. On the other hand, it is fair to say that the interpretation 
of a long-period "level" is somewhat forced, particularly for the shorter sample lengths. The determination of $f_{o}(P)$ is also more difficult for the shorter sample lengths.

Similarly, the lower sequence of diagrams is for the $S$ wave (NS) of the Turkey earthquake at HKC. Spectrum 2 is considered to be the best although $\Omega_{o}(S)$ and $f_{o}(S)$ can be recovered from either of the three sample lengths, provided that the suggested increase of $\Omega(\omega)$ at $f \simeq 0.01 \mathrm{~Hz}$ is attributed to the low dynamic magnification of the long-period instrument compounding the lower reliability of the spectral data at these periods. The spectral shift of $f_{o}(P)$ with respect to $f_{o}(S)$ can also be seen by comparing the high-frequency terminus of the $\Omega_{o}(P)$ line and the $\Omega_{o}(S)$ line.
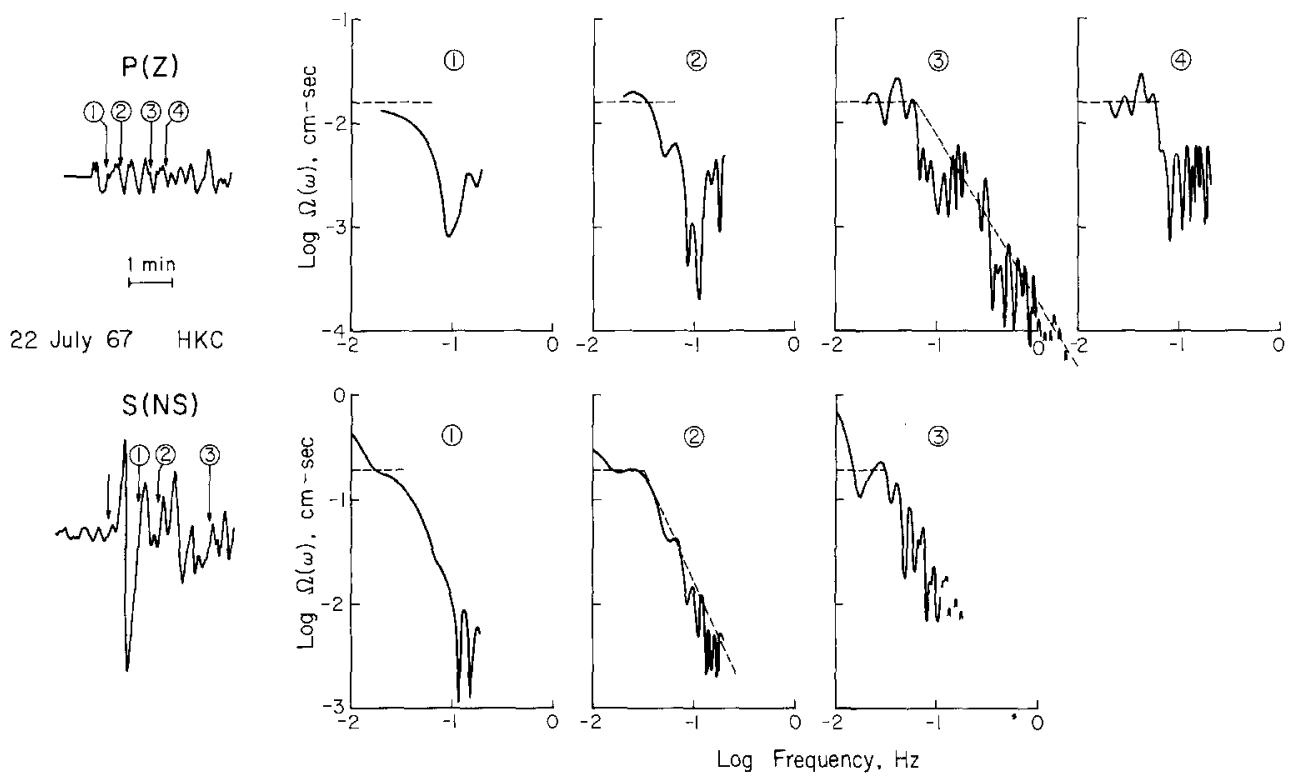

Fig. 2. Effect of sample length on computed body-wave spectra and $\Omega_{o}-f_{o}$ approximation for $P$ and $S$ waves at station $\mathrm{HKC}$, Turkey earthquake.

This and similar analyses of sample length variations for other phases indicate that, in general, $\Omega_{o}$ can be estimated to a factor of $2\left( \pm 0.3\right.$ logarithmic units) and $f_{o}$ can be estimated to a factor of 1.5 ( \pm 0.2 logarithmic units) from the spectral data. For the data considered in this study, the choice of sample length is the major uncertainty in the spectral determinations $\Omega_{o}$ and $f_{o}$. A sample length of several times the period corresponding to $f_{o}$ is generally necessary for a reliable determination of $\Omega_{o}$. While this criterion is generally met, the resulting sample lengths often include multiple arrivals and sourceto-station crustal reverberations. These effects are not explicitly accounted for and are regarded as the major source of noise. Some of these factors will be discussed in more detail during and following a presentation of the observational results.

References to $P$ waves or $P$-wave spectra will always mean the $P$ wave recorded on the vertical instrument. Similarly, references to $S$ waves or $S$-wave spectra imply $S$ waves recorded on the horizontal components. In general, the one horizontal component receiving the predominance of $S H$ motion will be the one under consideration. The spectra as they appear in the remainder of the paper are corrected only for seismic attenuation following Julian and Anderson (1968) and the instrument response. The earthquakes considered here are large enough so that $f_{o} \leqq 0.2 \mathrm{~Hz}$ in all cases, The $Q$ structure of Julian and Anderson (1968) affects amplitudes in this frequency range hardly at all. 


\section{ANALYSIS OF THREE EARTHQUAKES}

In this section, we will present body-wave signals, their spectra, and a summary of the spectral parameters derived from them for the three earthquakes mentioned previously. Determinations of seismic moments and source dimensions calculated from teleseismic body-wave spectra and field evidence will be noted for each event as a part of the presentation of data. With the basic results of this study in hand, we will then discuss the several corrections to the spectral approximations $\Omega_{0}$ and $f_{0}$ (including the effects of radiation pattern, geometrical spreading, crustal transfer function, multiple arrivals, and directivity function) necessary to obtain $M_{o}$ and $r$. Together with a discussion of the accuracy of the field measurements, we can then assess the errors of the several estimates of $M_{o}$ and $r$.

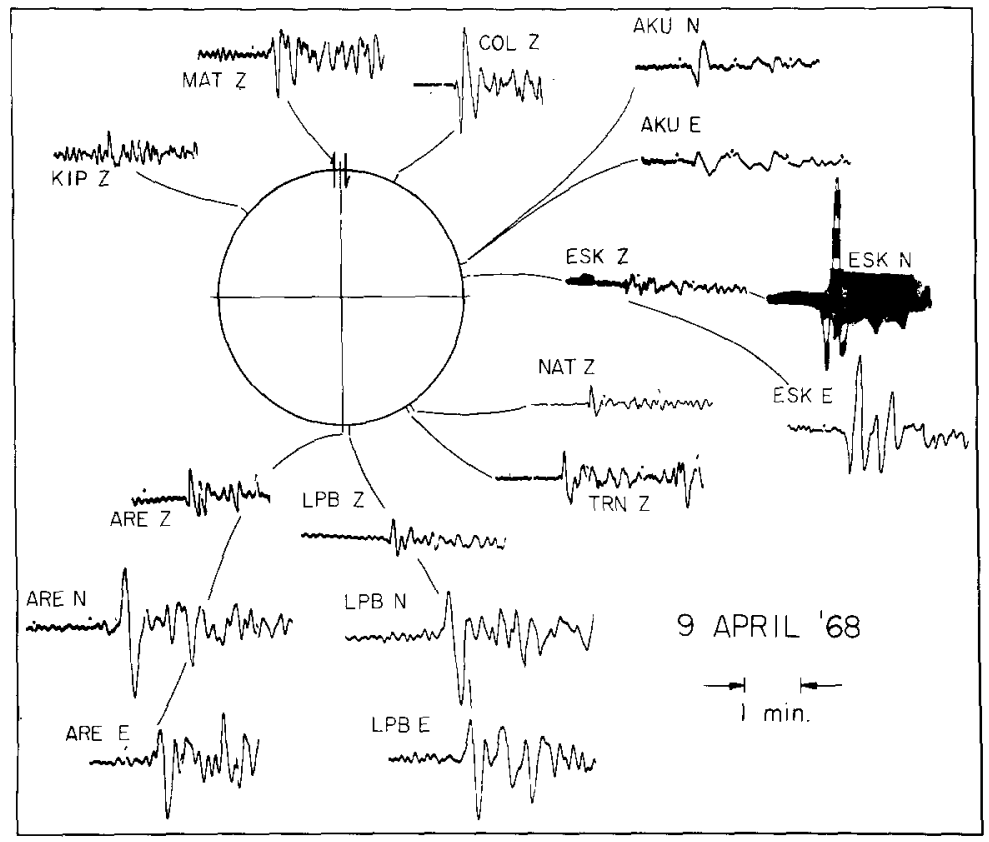

FIG. 3. Long-period $P$ and $S$ waves, California earthquake, presented with respect to azimuth of fault trace, N $48^{\circ} \mathrm{W} . P$ waves denoted by $Z$ (vertical) and $S$ waves by $N$ (north-south) and/or E (east-west).

Borrego Mountain, California, earthquake. This earthquake occurred in the San Jacinto fault zone in southern California on April 9, 1968, and had a (local) magnitude of 6.4. Its $33-\mathrm{km}$ fault trace consisted of two northwest-trending, en-echelon elements. The maximum horizontal slip on the northern segment was $38 \mathrm{~cm}$ and on the southern segment was $20 \mathrm{~cm}$. Vertical displacements were generally small but locally had values of up to $20 \mathrm{~cm}$ (Allen et al., 1968).

For the field parameters of this event, we take $\bar{u}=\frac{3}{4} u_{\max }$ (Brune and Allen, 1967) $=$ $30 \mathrm{~cm}$, and neglect the vertical displacement, $L=33 \mathrm{~km}$, and $\mu=3.3 \times 10^{11}$ dyne-cm; the depth of faulting is taken as $11 \mathrm{~km}$, the hypocentral depth of the main shock given by Allen and Nordquist (1971). With these parameters, $M_{o}(F)=3.6 \times 10^{25}$ dyne-cm, and $L / 2(F)=17 \mathrm{~km}$. The zone of intense aftershock activity defined a fault length of $45 \mathrm{~km}$ (Hamilton, 1971). Although this need not imply that slip resulting from the main shock actually occurred on the $45-\mathrm{km}$ segment, our choice of $L$ may be underestimated by a factor of 1.3. The depth of the deepest aftershock that occurred along the broken segment was $12 \mathrm{~km}$ (Hamilton, 1971) compared to our choice of $h=11 \mathrm{~km}$. 
To determine $M_{o}$ and $r$ from teleseismic body-wave spectra, we have chosen $8 P$ waves and $4 S$ waves (both horizontal components). The long-period $P$ and $S$ signals are presented in Figure 3, and the resulting $P$-wave spectra are presented in Figure 4 , both as azimuth plots with respect to the local strike of the San Jacinto fault $\left(\mathrm{N} 48^{\circ} \mathrm{W}\right)$. The $\Omega_{o}-f_{o}$ fit to the $P$-wave spectra is indicated by the dashed lines. The short-period data are important with respect to the determination of $f_{o}(P)$, since $f_{o}(P)(0.1-0.2 \mathrm{~Hz})$ occurs at frequencies somewhat higher than that of the peak response of the long-period instrument.

Figure 5 presents the $S$-wave spectra with the $\Omega_{o}-f_{o}$ fit in dashed lines. Because of the spectral shift of $f_{o}(S)$ with respect to $f_{o}(P), f_{o}(S)$ occurs very close to the frequency of peak

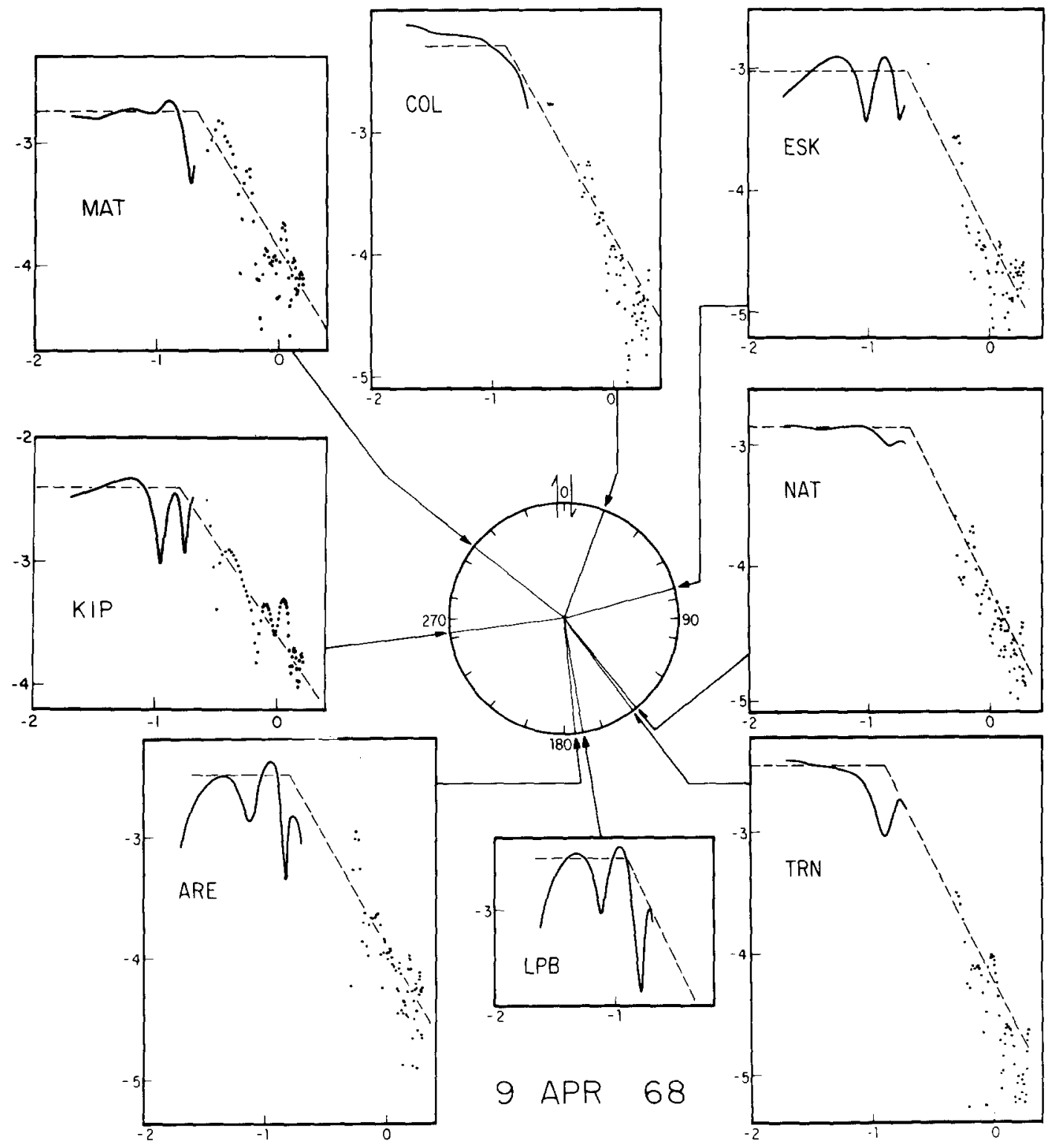

Flg. 4. $P$-wave spectra, California earthquake, presented with respect to azimuth of fault trace, $\mathrm{N} 48^{\circ} \mathrm{W}$. Solid lines are spectral data from long-period instrument; points are spectral data from shortperiod instrument, a convention to be used in Figures $5,7,8,10$, and 11 as well. Vertical scales are $\log _{10}$ amplitude spectral density $(\mathrm{cm}-\mathrm{sec})$; horizontal scales are $\log _{10}$ frequency $(\mathrm{Hz})$. 
response for the long-period instrumentation. $f_{o}(S)$ could be defined on the basis of the long-period data alone [with the possible exception of $E K S S(\mathrm{NS})]$. This circumstance was fortunate since good short-period data were generally not available at the stations chosen. Both $P$ - and $S$-wave spectra were obtained from sample lengths less than $65 \mathrm{sec}$.

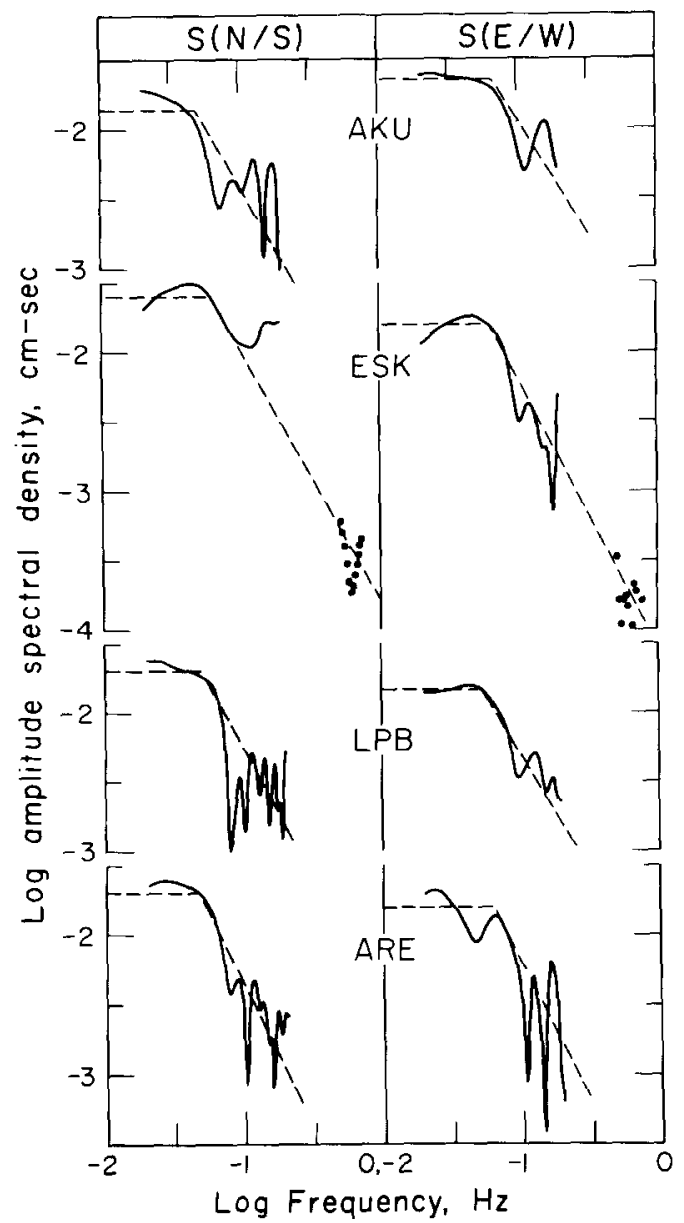

Fig. 5. $S$-wave spectra, California earthquake. Horizontal instrument component as indicated.

A summary of $\Omega_{o}$ and $f_{o}$ for both the $P$ and $S$ spectra is given in Table 2, along with the determination of $M_{o}$ and $r$ using (4) and (5) or (6) and (7). The radiation pattern correction was made on the basis of a vertical plane striking parallel to the San Jacinto fault $\left(\mathrm{N} 48^{\circ} \mathrm{W}\right)$. Table 3 summarizes the average moment and fault-length determinations; references to Brune imply the use of (5) or (7). Also listed are estimates for $r$ and $A_{o}$ computed from the models of Berckhemer and Jacob (1968) and Kasahara (1957). The fault length estimated from these models is low by a factor of 4 from the observed fault length. In contrast, the fault length estimated from $f_{o}(S)$ and (5) (Brune, 1970) or $f_{o}(P)$ and (7) are in good agreement with the observed length of surface ground breakage, the average $S$-wave fault length being about 30 per cent high and the average $P$-wave fault length being about 20 per cent low. Individual variation of $f_{o}(P)$ can be grossly correlated with azimuth from the fault plane's strike; this will be presented in the discussion below. 
TABLE 2

$P$ - and $S$-Wave Spectral Data, California Earthquake

\begin{tabular}{|c|c|c|c|c|c|c|c|c|c|}
\hline Station & $\begin{array}{c}\text { Distance } \\
\text { (deg) }\end{array}$ & $\begin{array}{c}\text { Station } \\
\text { Azimuth } \\
\text { (deg) }\end{array}$ & Phase & Component & $\begin{array}{c}\Omega_{o} \\
\left(10^{\left.-\frac{2}{2} \mathrm{~cm}-\mathrm{sec}\right)}\right.\end{array}$ & $\begin{array}{l}f_{o} \\
(\mathrm{~Hz})\end{array}$ & $\stackrel{r}{r})$ & $\left(10^{25} \stackrel{M_{o}}{\mathrm{dyne-cm}}\right)$ & $\underset{\left(20^{20} \mathrm{ergs}\right)}{E_{s}}$ \\
\hline $\mathrm{AKU}$ & 63.4 & 27 & $S$ & EW & 2.2 & 0.069 & 19 & \multirow[b]{2}{*}{5.9} & \multirow[b]{2}{*}{1.0} \\
\hline AKU & - & - & $S$ & NS & 1.4 & 0.05 & 26 & & \\
\hline ESK & 74.9 & 33 & $\mathbf{P}$ & Z & 0.05 & 0.20 & 11 & - & - \\
\hline ESK & - & - & $\mathrm{S}$ & EW & 1.6 & 0.063 & 21 & \multirow[b]{2}{*}{8.1} & \multirow[b]{2}{*}{2.1} \\
\hline ESK & - & - & $S$ & NS & 2.5 & 0.063 & 21 & & \\
\hline NAT & 85.4 & 99 & $\mathbf{P}$ & Z & 0.14 & 0.22 & 10 & 11.0 & 一 \\
\hline TRN & 54.8 & 101 & $\mathbf{P}$ & Z & 0.35 & 0.126 & 18 & 11.0 & - \\
\hline LPB & 67.4 & 129 & $\mathrm{P}$ & Z & 0.33 & 0.12 & 19 & - & - \\
\hline LPB & - & 一 & $S$ & EW & 1.4 & 0.052 & 25 & \multirow[b]{2}{*}{7.0} & \multirow[b]{2}{*}{0.85} \\
\hline LPB & - & - & $S$ & NS & 2.0 & 0.05 & 26 & & \\
\hline ARE & 65.2 & 132 & $\mathrm{P}$ & $\mathrm{Z}$ & 0.32 & 0.16 & 14 & - & - \\
\hline ARE & - & - & $\mathrm{S}$ & EW & 1.6 & 0.063 & 21 & \multirow[b]{2}{*}{5.5} & \multirow[b]{2}{*}{0.70} \\
\hline ARE & - & - & $S$ & NS & 2.0 & 0.047 & 28 & & \\
\hline KIP & 38.8 & 263 & $\mathrm{P}$ & z & 0.40 & 0.16 & 14 & 7.4 & - \\
\hline MAT & 81.9 & 308 & $P$ & Z & 0.18 & 0.21 & 11 & - & - \\
\hline $\mathrm{COL}$ & 37.1 & 338 & $P$ & Z & 0.50 & 0.126 & 18 & 12.0 & - \\
\hline
\end{tabular}

TABLE 3

Summary of Seismic-Moment and Source-Dimension Determinations, California Earthquake

\begin{tabular}{lccc}
\hline & $\begin{array}{c}M_{o} \\
\left(10^{25} \begin{array}{c}\text { dyne-cm }) \\
\text { Surface rupture }\end{array}\right.\end{array}$ & $\begin{array}{c}\text { Source Dimension, } \\
\text { L/2, } \\
(\mathrm{km})\end{array}$ & $\begin{array}{c}\text { Area, } \\
A_{\mathrm{o}} \\
\left(\mathrm{km}^{2}\right)\end{array}$ \\
\hline Aftershock zone & 3.6 & 17 & $363^{*}$ \\
$P$ wave (Brune, 1970) & 4.9 & 22 & $540 \dagger$ \\
$S$ wave (Brune, 1970) & 10.0 & 14 & 615 \\
$P$ wave (Kasahara, 1957) & 6.6 & 23 & 1660 \\
$P$ wave (Berckhemer and Jacob, 1968) & - & $4.1 \ddagger$ & $53 \ddagger$ \\
\hline
\end{tabular}

\footnotetext{
${ }^{*} h=11 \mathrm{~km}$.

$\dagger h=12 \mathrm{~km}$.

$\ddagger r=0.7 \alpha / 2 \pi f_{o}(P) ; A_{0}=\pi^{2} \vec{r}^{2}$.

$\S A_{0}=c^{2} \mid f_{0}{ }^{2}(P) 2 \pi, c=$ rupture velocity, taken to be $3 \mathrm{~km} / \mathrm{sec} ; \bar{r}=\sqrt{A_{0} / \pi}$.
} 
Similarly, the seismic moments as computed from the $P$-wave and $S$-wave spectra are consistent with each other and agree with the moment computed from the field data, the field moment being low by a factor of 2 to 3 .

Mudurnu Valley, Turkey, earthquake. This earthquake occurred on July 22, 1967 on the Anatolian fault in northwestern Turkey; it has been assigned a magnitude of 7.1. Eighty kilometers of fresh faulting attributed to this event were accompanied by a maximum horizontal (right-lateral) displacement of $190 \mathrm{~cm}$ and a maximum vertical (north side down) displacement of $120 \mathrm{~cm}$ (Ambraseys and Zatopek, 1969). While these authors

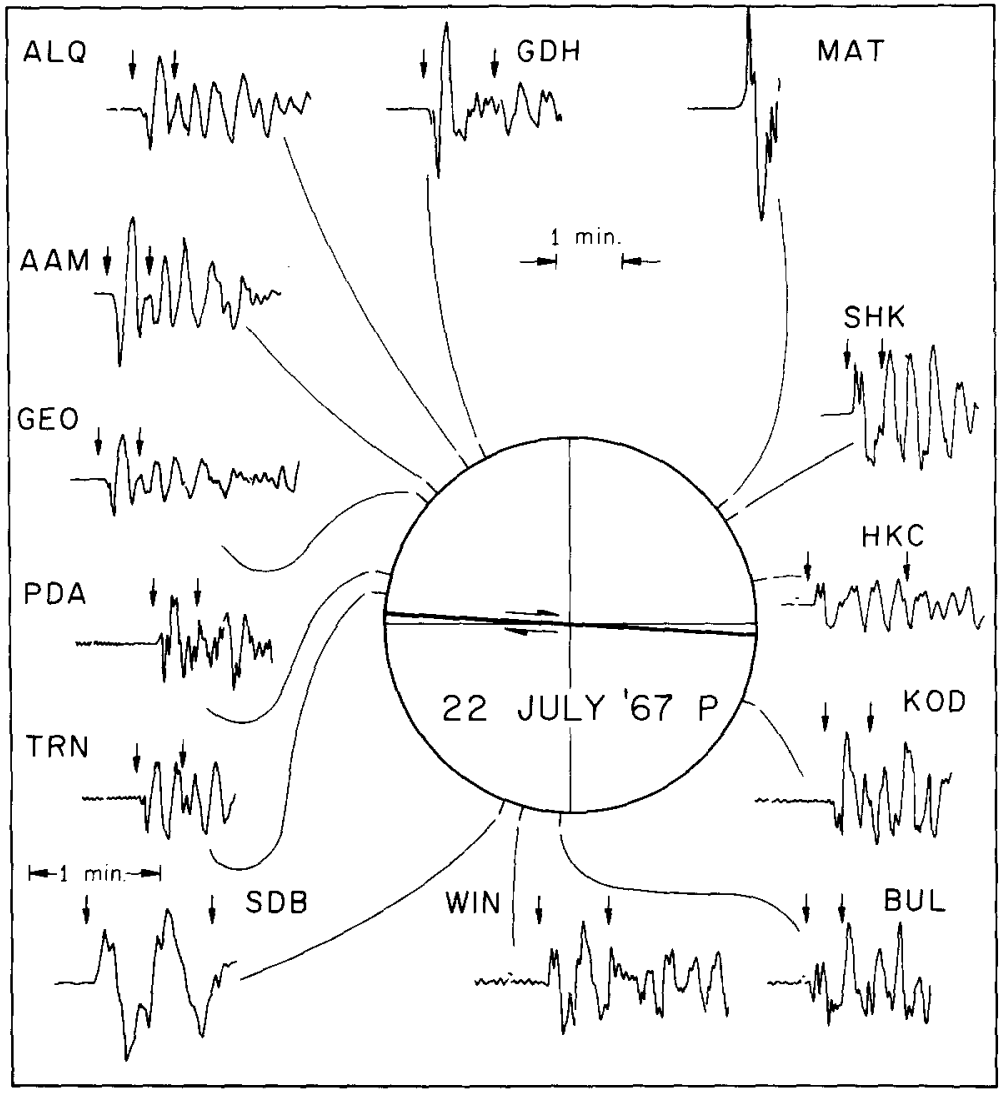

FIG, 6. Long-period $P$-waves, Turkey earthquake, presented with respect to station azimuth. Preferred fault plane of D. P. McKenzie (personal communication) as indicated. Note minute mark for SDB.

indicated that preliminary results indicated a focal depth of less than $10 \mathrm{~km}$, this estimate is subject to considerable unccrtainty and, in any case, need only locate the point of initial rupture. On the basis of this event's similarity (in terms of its magnitude, seismic moment and fault length) to the Iran earthquake (sea below), we feel a more realistic depth of faulting is $20 \mathrm{~km}$. Taking $h=20 \mathrm{~km}, L=80 \mathrm{~km}, \bar{u}=140 \mathrm{~cm}$, and $\mu=$ $3.3 \times 10^{11}$ dyne- $\mathrm{cm}^{2}$, we estimate $M_{o}(F)$ for this event to be $7.4 \times 10^{26}$ dyne-cm; we have taken $L / 2(F)=40 \mathrm{~km}$.

To estimate the seismic moment and source dimension from teleseismic body-wave spectra, we have chosen $13 P$ waves and $8 S$ waves ( 5 stations). The $P$ waves are presented with respect to station azimuth in Figure 6; the strike azimuth of the preferred slip plane 
(D. P. McKenzie, personal communication) is as indicated. On the focal sphere, this plane is given by $\varphi=93^{\circ}, \delta=90^{\circ}$.

The resulting $P$-wave spectra are presented in Figure 7 . The $\Omega_{o}-f_{o}$ fit has not been included (nor will it be for the remainder of the spectra to be presented), so that the trend of the data can be discussed without reference to our choice of approximation. Generally, the spectral amplitudes increase with decreasing frequency until frequencies of $4-6 \times 10^{-2} \mathrm{~Hz}$ are reached. In this frequency range, there is a definite tendency for the spectral amplitudes to attain maximum values, which we interpret as $\Omega_{o}$.
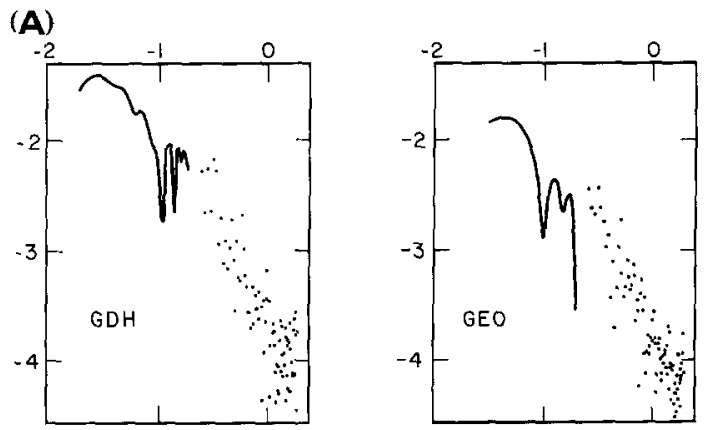

(B)
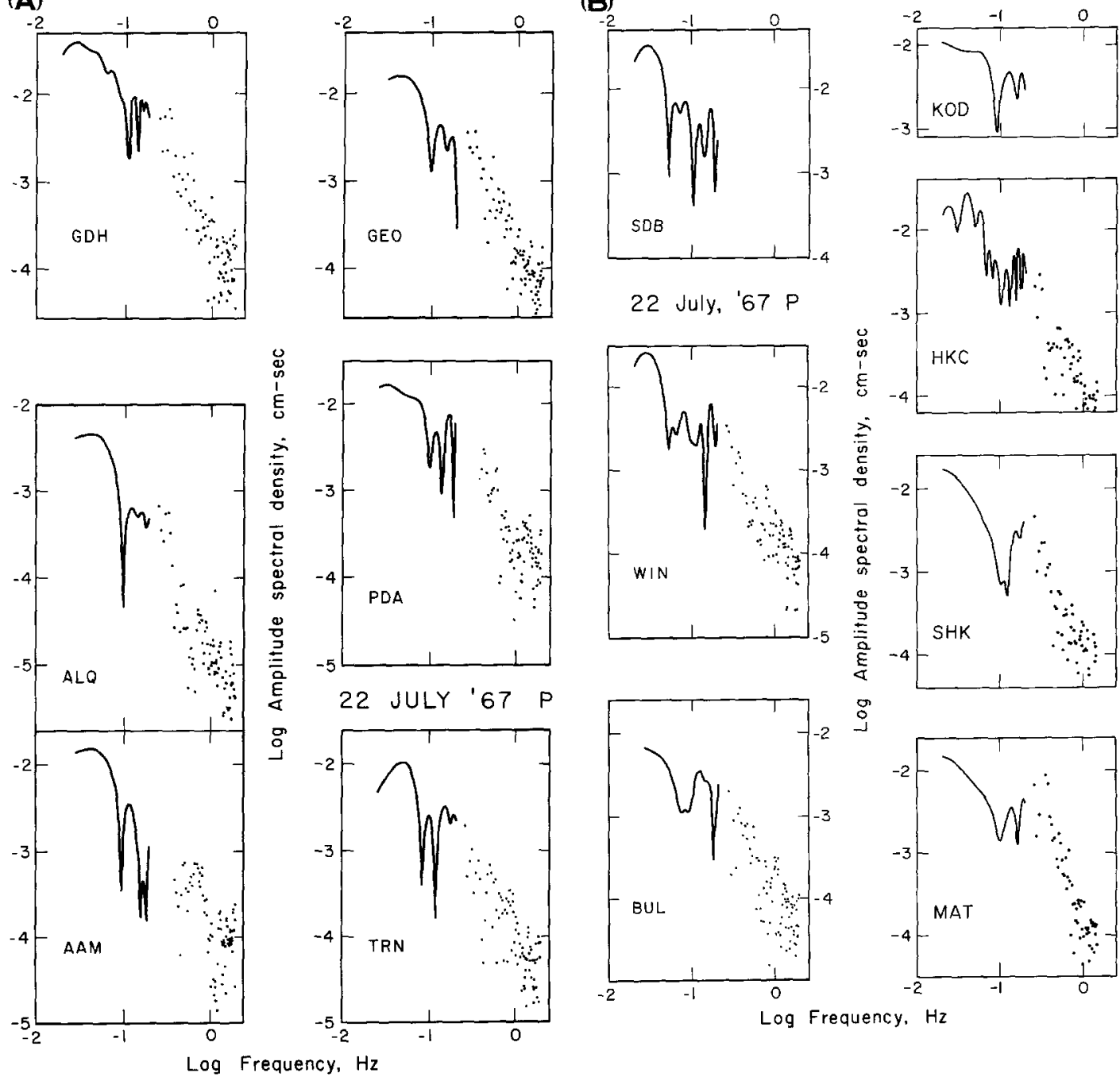

$\stackrel{0}{\circ}$

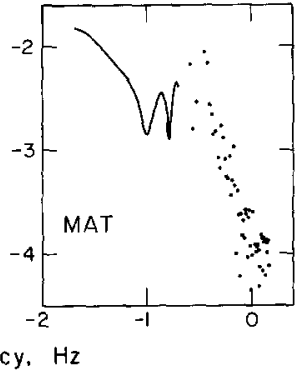

FIG. 7. $P$-wave spectra, Turkey earthquake.

We can illustrate again the effect of short sample lengths by comparing sample lengths (Figure 6) with resulting spectra (Figure 7) for the $P$ wave of the Turkey earthquake at stations BUL, KOD, HKC, SHK, and MAT. Certainly, the sample length chosen for BUL excludes the majority of $P$-wave motion. As expected, $\Omega_{o}$ is relatively low, by a factor of 2 or 3 . By consequence of the $\Omega_{o}-f_{o}$ fit, $f_{o}(P)$ is correspondingly higher (see discussion below). But even this obviously poor choice of sample length still yields 
$\Omega_{o}-f_{o}$ data that are not dramatically inconsistent with other estimates. On the basis of our experience with $P$ waves at HKC (Figure 2), we might also suspect that $\Omega_{o}(P)$ is underestimated at MAT and SHK, since the sample lengths chosen were relatively short. (Note the narrow azimuth range for HKC, SHK, and MAT, Figure 6; the $P$ wave at MAT could not be unambiguously followed for times longer than that indicated.) Particularly at MAT, the matching of short- and long-period data is not good, but the consistency of the data is at least fair.

Sample lengths chosen for long-period $P$-waves were generally near 60 seconds; spectral amplitudes were computed only for $f \geqq 0.02 \mathrm{~Hz}$. While it would be desirable to have spectral data at longer periods to define $\Omega_{o}$ more adequately, we feel that the trend of the data in the frequency range $4-6 \times 10^{-2} \mathrm{~Hz}$ is real. Values of $\Omega_{o}(P)$ and $f_{o}(P)$ are listed in Table 4, together with the resulting $M_{o}(P)$ and $r(P)$ determinations.

TABLE 4

P-Wave Spectral Data, Turkey Earthquake

\begin{tabular}{|c|c|c|c|c|c|c|c|c|}
\hline Station & $\begin{array}{l}\text { Distance } \\
\text { (deg) }\end{array}$ & $\begin{array}{l}\text { Station } \\
\text { Azimuth } \\
\text { (deg) }\end{array}$ & $\left(10^{-2} \mathrm{~cm}-\mathrm{sec}\right)$ & $\left(10^{-2} \mathrm{~Hz}\right)$ & $\stackrel{r}{r}$ & $\begin{array}{c}M_{o} \\
\text { (1026 dyne-cm) }\end{array}$ & $\stackrel{\mathscr{R}_{0 \phi}}{(P)}$ & $\begin{array}{c}15-100 \\
\text { Gain }\end{array}$ \\
\hline MAT & 78.3 & 51.7 & 1.0 & - & - & 4.4 & 0.16 & 3000 \\
\hline SHK & 76.2 & 56.4 & 1.0 & 4.0 & 56 & 7.8 & 0.10 & 1500 \\
\hline $\mathrm{HKC}$ & 70.8 & 76.8 & 1.5 & 6.3 & 36 & 14.5 & 0.05 & 750 \\
\hline KOD & 50.9 & 113.1 & 0.79 & 6.0 & 37 & 2.7 & 0.13 & 1500 \\
\hline BUL & 60.5 & 182.0 & 0.63 & 7.9 & 28 & - & 0.01 & 1500 \\
\hline WIN & 64.2 & 194.3 & 1.8 & 6.6 & 34 & 15.6 & 0.07 & 1500 \\
\hline SDB & 57.5 & 200.2 & 2.5 & 4.0 & 56 & 15.2 & 0.10 & 1500 \\
\hline TRN & 85.0 & 279.6 & 0.79 & 6.3 & 36 & - & 0.03 & 1500 \\
\hline PDA & 43.4 & 285.3 & 1.3 & 6.6 & 34 & 5.5 & 0.10 & 750 \\
\hline GEO & 77.2 & 310.5 & 1.3 & 6.6 & 34 & 9.0 & 0.10 & 750 \\
\hline AAM & 78.5 & 316.5 & 1.3 & 6.3 & 36 & 9.0 & 0.10 & 1500 \\
\hline ALQ & 95.2 & 326.1 & 0.38 & 6.0 & 37 & 7.7 & 0.06 & 3000 \\
\hline $\mathrm{GDH}$ & 50.8 & 332.8 & 2.9 & 5.0 & 45 & 8.9 & 0.14 & 750 \\
\hline
\end{tabular}

$S$-wave spectra are presented in Figure 8. (The $S$ waves for the Turkey and Iran earthquakes are not presented for economy of space.) For the $S$ phase, longer sample lengths have been necessary to define $\Omega_{o}$ and $f_{o}$ adequately. $f_{o}(S)$ is in the range 2-3x $10^{-2} \mathrm{~Hz}$, with the exception of GDH (NS) (Figure 8 and Table 5), shifted toward lower frequencies with respect to $f_{o}(P)$, in accord with Figure 1. Sample lengths vary from 80 to $120 \mathrm{sec}$, the longer sample lengths undoubtedly including the $S c S$ arrival for stations with $\Delta \geqq 60^{\circ}$. The $S c S$ arrival at HKC can be clearly seen in Figure 2 . Values of $\Omega_{o}(S)$ and $f_{o}(S)$ are listed in Table 5, together with the resulting $M_{o}(S)$ and $r(S)$ determinations.

A summary of the seismic moment and source dimension determinations for this earthquake is presented in Table 6 . The $\mathscr{R}_{\theta \varphi}$ correction has been made on the basis of the fault-plane solution of D. P. McKenzie (personal communication). The agreement between the several estimates for either parameter is excellent.

Dasht-e-Bayäz, Iran, earthquake. This earthquake occurred on August 31, 1968 in east-central Iran; it has been assigned a magnitude of 7.2 . It is associated with $80 \mathrm{~km}$ of east-west faulting, accompanied by a maximum horizontal (left-lateral) displacement 


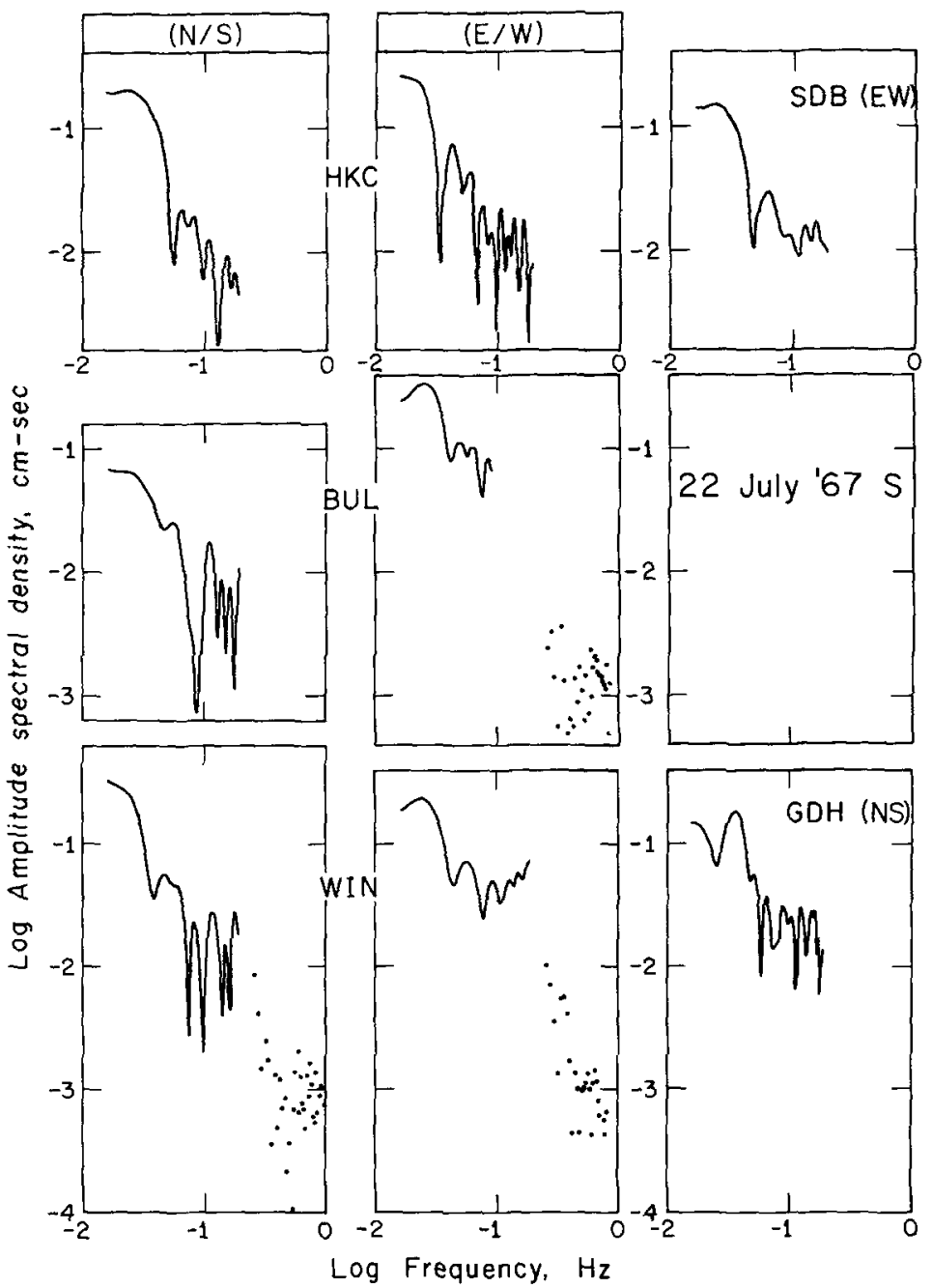

Fig, 8. S-wave spectra, Turkey earthquake. Horizontal instrument component as indicated.

TABLE 5

$S$-Wave Spectral Data, Turkey Earthquake

\begin{tabular}{lccccc}
\hline $\begin{array}{c}\text { Station } \\
\text { (Phase) }\end{array}$ & $\begin{array}{c}\Omega_{0} \\
\left(10^{-1} \mathrm{~cm}-\mathrm{sec}\right)\end{array}$ & $\begin{array}{c}f_{0} \\
\left(10^{-2} \mathrm{~Hz}\right)\end{array}$ & $\begin{array}{c}r \\
(\mathrm{~km})\end{array}$ & $\begin{array}{c}M_{0} \\
\left(10^{22} \mathrm{~d} \text { dyne-cm }\right)\end{array}$ & $\begin{array}{c}E_{s}(S) \\
\left(\times 10^{21} \mathrm{ergs}\right)\end{array}$ \\
\hline HKC (NS) & 2.0 & 3.0 & 43 & 8.9 & 2.8 \\
HKC(EW) & 2.5 & 2.1 & 62 & - & - \\
BUL (NS) & 0.63 & 2.6 & 50 & - & - \\
BUL (EW) & 2.9 & 3.0 & 43 & 15.1 & 8.0 \\
WIN (NS) & 2.5 & 2.5 & 52 & - & - \\
WIN (EW) & 2.1 & 2.9 & 45 & 7.4 & 1.7 \\
SDB (EW) & 1.3 & 2.8 & 46 & 3.6 & 0.37 \\
GDH (EW) & 1.3 & 4.0 & 33 & 7.6 & 4.8 \\
\hline
\end{tabular}

* Epicentral distance, station azimuth data in Table 4. 
TABLE 6

Summary of Seismic Moment and Source Dimension Determinations, TURKEY EARTHQUAKe

\begin{tabular}{lcl}
\hline \multicolumn{1}{c}{ Source Parameter } & Value & \multicolumn{1}{c}{ Comments } \\
\hline$M_{o}(F)\left(\times 10^{26}\right.$ dyne-cm) & 7.4 & From data of Ambraseys and Zatopek (1969) \\
$\bar{M}_{o}(P)\left(\times 10^{26}\right.$ dyne-cm) & 9.1 & Average of 11 determinations (Table 3) \\
$\bar{M}_{o}(S)\left(\times 10^{26}\right.$ dyne-cm) & 8.5 & Average of 5 determinations (Table 4) \\
$L / 2(F)(\mathrm{km})$ & 40 & Ambraseys and Zatopek (1969) \\
$\bar{r}(P) \quad(\mathrm{km})$ & 39 & Average of 12 determinations (Table 3) \\
$\bar{r}(S) \quad(\mathrm{km})$ & 48 & Average of 8 determinations (Table 4) \\
\hline
\end{tabular}

of $450 \mathrm{~cm}$ and a maximum vertical (north side down) displacement of $250 \mathrm{~cm}$. A preliminary estimate of the focal depth of the main shock indicated it was less than $15 \mathrm{~km}$ (Ambraseys and Tchalenko, 1969).

Crampin (1969) located aftershocks of this earthquake using $S$ - $P$ times and azimuth determinations based on the relative amplitudes of the $S$-waves recorded on horizontal components. He obtained focal depths of $20 \mathrm{~km}$ for events located in the center of the fault zone and focal depths of $25 \mathrm{~km}$ for events at the extremities of the observed ground breakage; the locations were estimated to be accurate to 5 to $10 \mathrm{~km}$.

With a depth of faulting of $20 \mathrm{~km}$, the fault surface has an area of $1.6 \times 10^{13} \mathrm{~cm}^{2}$. We take $\bar{u}=340 \mathrm{~cm}$ to obtain $M_{o}(F)=18 \times 10^{26}$ dyne-cm, and $L / 2(F)=40 \mathrm{~km}$.

Body-wave spectra have been obtained from $P$ waves recorded at 16 WWSSN stations and from $S$ waves recorded at 6 stations. The $P$ waves are presented with respect to station azimuth in Figure 9. The strike azimuth of the preferred slip plane (from the focal mechanism solution of Niazi, 1969) is indicated. The $P$-wave spectra are presented in Figure 10, and values of $\Omega_{o}(P)$ and $f_{o}(P)$ for them are given in Table 7, along with

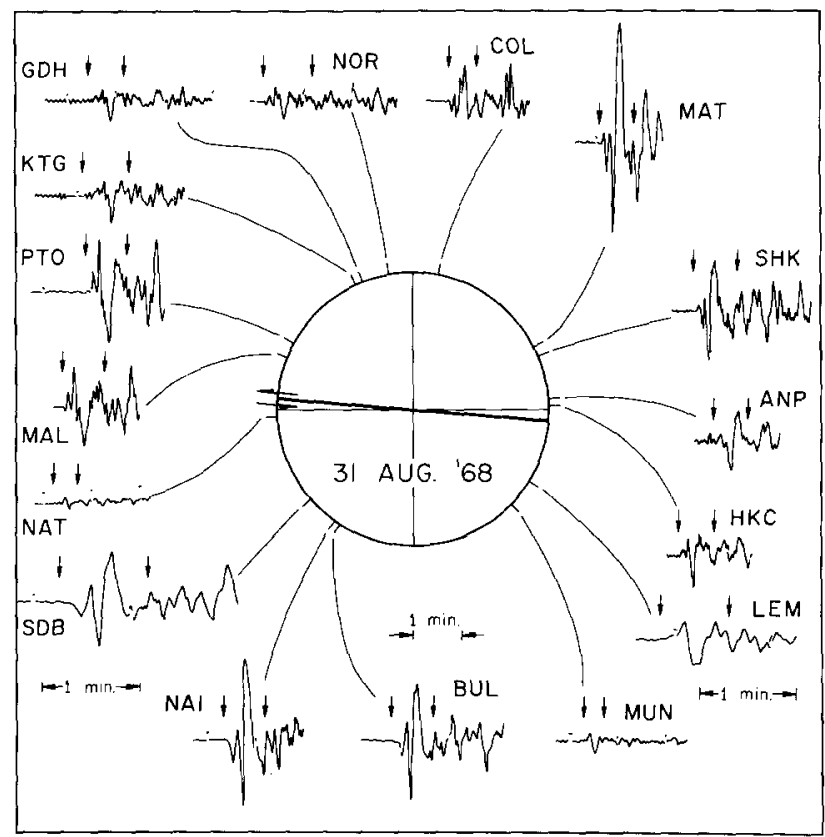

FIG. 9. Long-period $P$-waves, Iran earthquake, presented with respect to station azimuth. Preferred fault plane of Niazi (1969) as indicated. Note minute marks for SDB and LEM. 
determinations of $M_{o}(P)$ and $r(P) . S$-wave spectra are presented in Figure 11, and values of $\Omega_{0}(S)$ and $f_{0}(S)$ are given in Table 8 , together with determinations of $M_{0}(S)$ and $r(S)$.

The Iran earthquake and the Turkey earthquake had comparable magnitudes, moments, and fault lengths. As would be expected, the spectral parameters $\Omega_{o}(P, S)$ and $f_{o}(P, S)$ for these two events correlate in a similar way. The $P$-wave spectra for this event are somewhat different from those of the Turkey earthquake in that the former do not decay so rapidly in the range $6 \times 10^{-2} \leqq f \leqq 2 \times 10^{-1} \mathrm{~Hz}$. That is, the rate of spectral decay $(\gamma)$ for $f \geqq f_{o}$ appears to increase from approximately 1 to 2 near 4 to $5 \mathrm{sec}$ for most of the $P$-wave spectra obtained for the Iran earthquake. While it is tempting to interpret this in terms of small $\varepsilon$ (Brune, 1970), the $S$-wave spectra for this event do not display the corresponding feature. Sample lengths chosen for signals from this event were similar
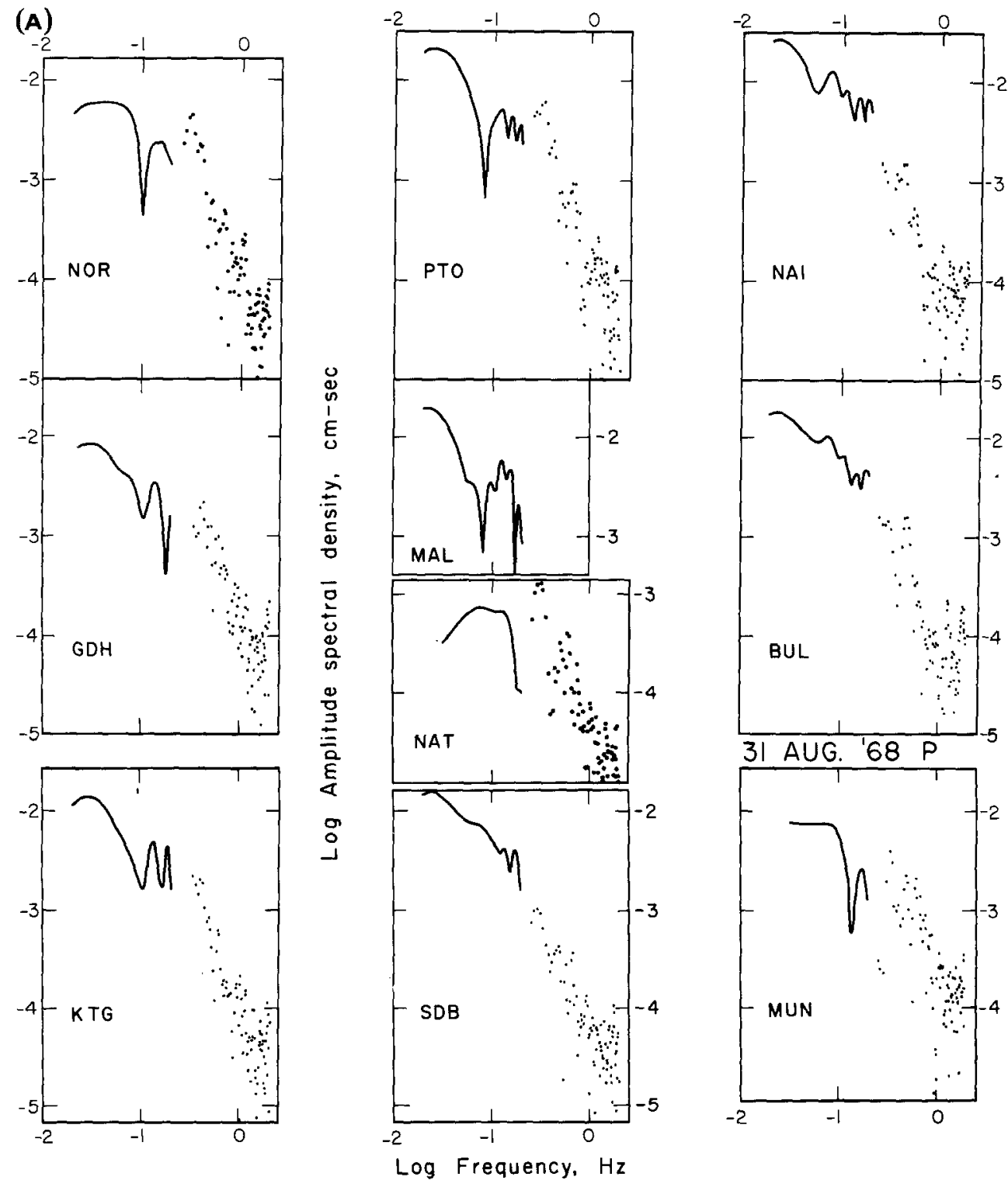

FIg. 10A. P-wave spectra, Iran earthquake. 

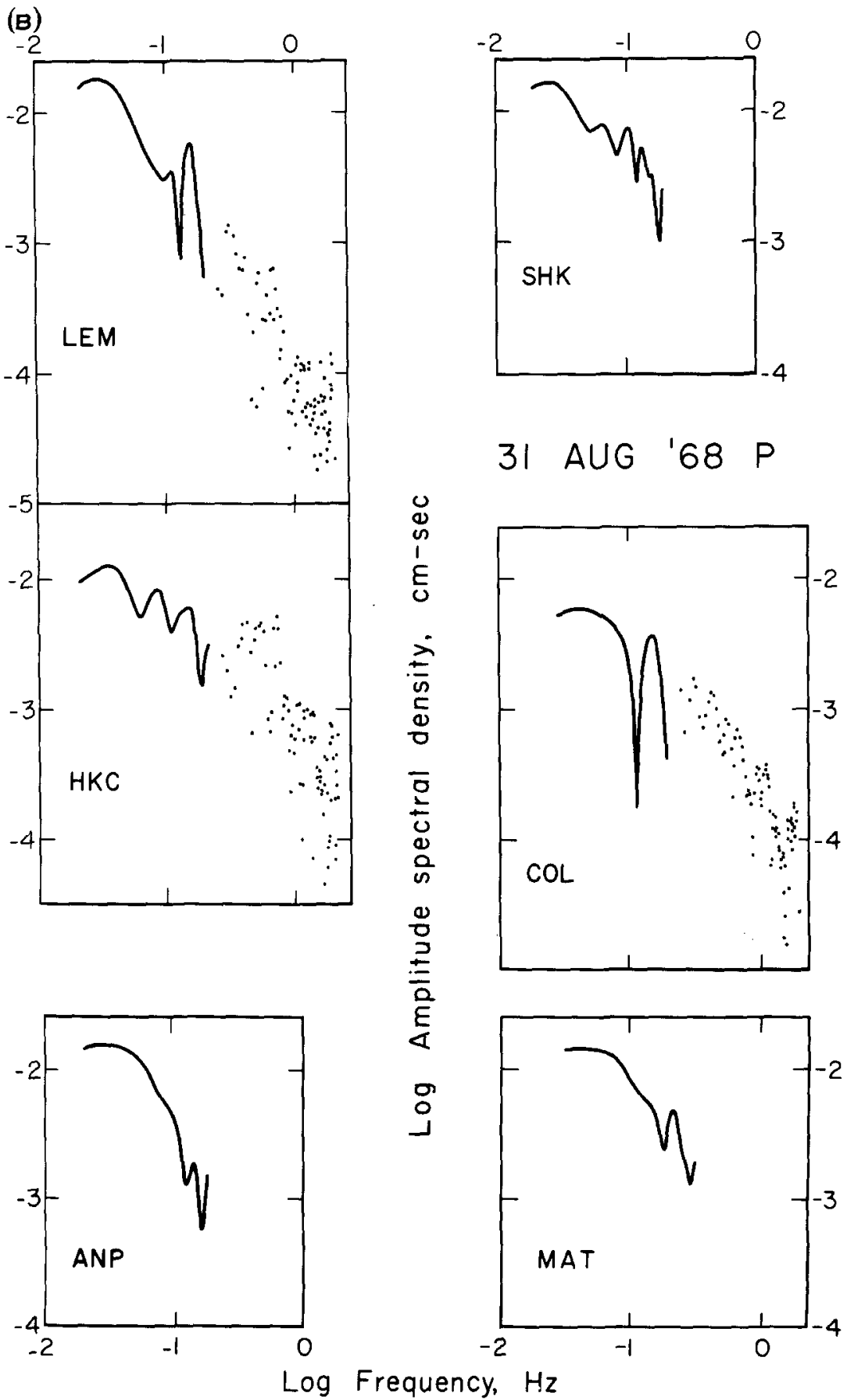

FIG. 10B. $P$-wave spectra, Iran earthquake.

to those chosen for the $P$ and $S$ waves of the Turkey earthquake. Table 9 gives a summary of seismic moment and source-dimension determinations for the Iran earthquake. The $\mathscr{R}_{\theta \varphi}$ correction has been made on the basis of the Niazi (1969) fault-plane solution. Agreement between the several estimates for $r$ is good, but moment determinations vary somewhat more than for the previous two earthquakes. 
TABLE 7

P.Wave Spectral Data, Iran Earthquake

\begin{tabular}{|c|c|c|c|c|c|c|c|c|}
\hline Station & $\begin{array}{c}\text { Distance } \\
\text { (deg) }\end{array}$ & $\begin{array}{c}\text { Station } \\
\text { Azimuth } \\
\text { (deg) }\end{array}$ & (10-2 $\left.{ }^{\Omega_{o}} \mathrm{cm-sec}\right)$ & $\left(10^{-f_{o}} \mathrm{~Hz}\right)$ & $\stackrel{r}{\mathrm{~km}}$ & $\left(\begin{array}{c}M_{0} \\
\left(10^{26} \text { dyne-cm) }\right.\end{array}\right.$ & $\begin{array}{l}\mathscr{R}_{\theta \phi} \\
(P)\end{array}$ & $\begin{array}{c}15-100 \\
\text { Gain }\end{array}$ \\
\hline $\mathrm{COL}$ & 79.2 & 11.2 & 0.50 & 6.3 & 36 & 4.8 & 0.075 & 1500 \\
\hline MAT & 63.1 & 62.6 & 1.4 & 6.3 & 36 & - & 0.028 & 3000 \\
\hline SHK & 59.7 & 66.7 & 1.4 & 4.0 & 56 & - & 0.015 & 1500 \\
\hline ANP & 54.5 & 81.5 & 1.3 & 5.5 & 41 & 8.7 & 0.083 & 750 \\
\hline HKC & 49.7 & 88.5 & 1.2 & 4.1 & 55 & 3.4 & 0.139 & 750 \\
\hline LEM & 61.5 & 121.7 & 1.6 & 4.0 & 56 & 3.5 & 0.353 & 750 \\
\hline MUN & 85.0 & 134.0 & 0.79 & 10.0 & 22 & 1.8 & 0.291 & 375 \\
\hline BUL & 61.0 & 212.7 & 1.4 & 4.0 & 56 & 一 & 0.047 & 1500 \\
\hline NAI & 40.7 & 215.0 & 2.2 & 3.2 & 70 & - & 0.025 & 1500 \\
\hline SDB & 64.9 & 229.4 & 1.3 & 3.5 & 64 & - & 0.025 & 1500 \\
\hline NAT & 96.0 & 267.9 & 0.063 & 32.0 & - & 一 & 0.0005 & 1500 \\
\hline MAL & 50.8 & 292.2 & 1.5 & 3.2 & 70 & - & 0.012 & 1500 \\
\hline PTO & 52.7 & 298.8 & 1.7 & 3.8 & 59 & - & 0.001 & 1500 \\
\hline KTG & 55.3 & 336.1 & 1.0 & 4.8 & 47 & - & 0.019 & 750 \\
\hline GDH & 65.9 & 338.8 & 0.71 & 4.0 & 56 & - & 0.026 & 750 \\
\hline NOR & 54.5 & 349.9 & 0.73 & 6.3 & 36 & 6.6 & 0.062 & 750 \\
\hline
\end{tabular}

TABLE 8

$S$-Wave Spectral Data, Iran Earthquake

\begin{tabular}{lccccc}
\hline $\begin{array}{c}\text { Station } \\
\text { (Phase) }\end{array}$ & $\begin{array}{c}\Omega_{o} \\
\left(10^{-1} \mathrm{~cm}-\mathrm{sec}\right)\end{array}$ & $\begin{array}{c}f_{o} \\
\left(10^{-2} \mathrm{~Hz}\right)\end{array}$ & $\begin{array}{c}r \\
(\mathrm{~km})\end{array}$ & $\begin{array}{c}M_{o} \\
\left(10^{26}\right.\end{array}$ dyne-cm) & $\begin{array}{c}E_{s}(S) \\
\left(\times 10^{21} \mathrm{ergs}\right)\end{array}$ \\
\hline HKC(NS) & 2.3 & 3.0 & 43 & 3.5 & 0.43 \\
HKC(EW) & 0.69 & 5.8 & - & - & - \\
SDB (NS) & 4.0 & 2.2 & 59 & - & - \\
SDB (EW) & 4.0 & 1.9 & 68 & - & - \\
MAL (NS) & 1.6 & 3.0 & 43 & 6.4 & 1.4 \\
MAL (EW) & 1.7 & 2.8 & 46 & - & - \\
PTO (NS) & 2.0 & 2.8 & 46 & 14.5 & 6.0 \\
PTO (EW) & 2.5 & 2.8 & 46 & - & - \\
GDH (NS) & 1.6 & 3.0 & 43 & 10.5 & 3.9 \\
NOR (NS) & 2.2 & 2.5 & 52 & 7.9 & 1.3 \\
NOR (EW) & 1.0 & 4.0 & 33 & - & - \\
\hline
\end{tabular}

* Epicentral distance, station azimuth data in Table 7.

TABLE 9

Summary of Seismic Moment and Source Dimension Determinations, IRAN EARTHQUAKE

\begin{tabular}{lcl}
\hline Source Parameter & Value & \multicolumn{1}{c}{ Comments } \\
\hline$M_{o}(F)\left(\times 10^{26}\right.$ dyne-cm) & 18.0 & From data of Ambraseys and Tchalenko (1969) \\
$\bar{M}_{o}(P)\left(\times 10^{26}\right.$ dyne-cm) & 4.8 & Average of 6 determinations (Table 6) \\
$\bar{M}_{o}(S)\left(\times 10^{26}\right.$ dyne-cm) & 8.6 & Average of 5 determinations (Table 7) \\
$L / 2(F)(\mathrm{km})$ & 40 & Ambraseys and Tchalenko (1969) \\
$\bar{r}(P) \quad(\mathrm{km})$ & 51 & Average of 15 determinations \\
$\bar{r}(S) \quad(\mathrm{km})$ & 48 & Average of 10 determinations \\
\hline
\end{tabular}




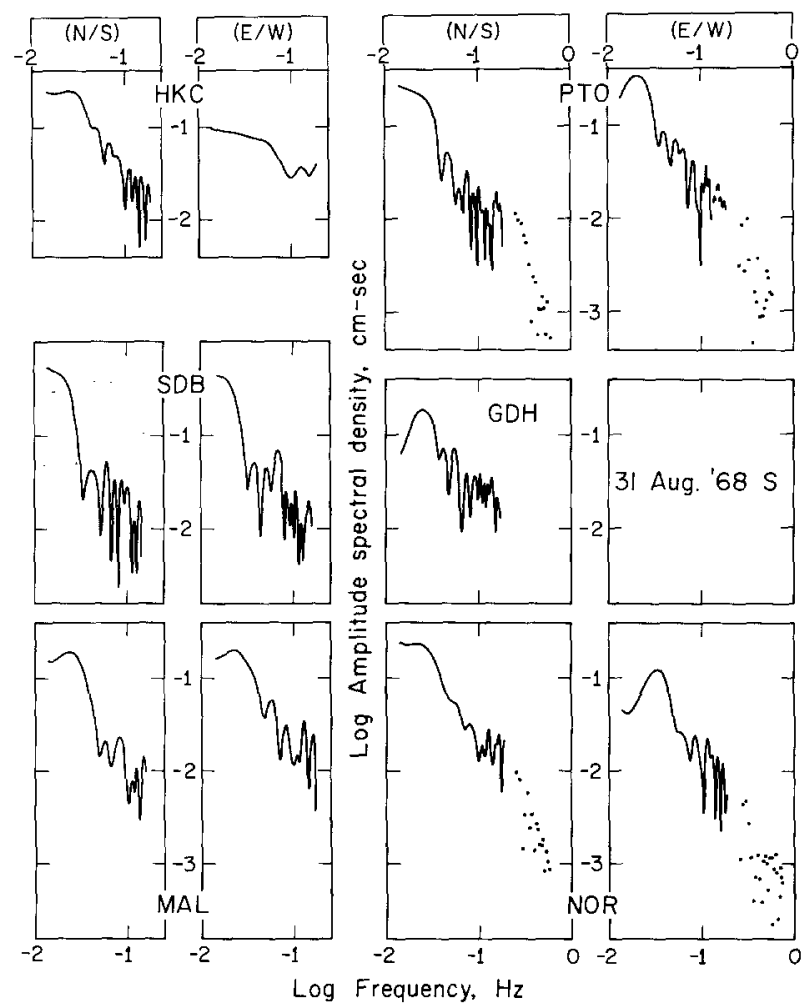

FIG. II S-wave spectra, Iran earthquake. Horizontal instrument component as indicated.

\section{Discussion}

Moment determination from teleseismic body-wave spectra. To determine $M_{o}$, it is necessary to correct the values of $\Omega_{o}$ (Tables $2,4,5,7,8$ ) for the radiation pattern, geometrical spreading, and crust and free surface effects. To sample the source at a single point $(\theta, \varphi)$ on the focal sphere, it is also necessary to remove all (multiple) arrivals other than the direct wave. The recorded signal can be expected, for example, to contain substation crustal reverberations, near-source free-surface reflections ( $p P, s S$, etc.), secondary arrivals (for instance, $P c p, S c S$ ) as well as the direct wave. $S$ waves in the radial direction are often followed by relatively strong $S$-coupled $P L$ waves (Chander et al., 1968).

The radiation pattern correction $\left(\mathscr{R}_{\theta \varphi}\right)$ for the $P$ waves is particularly difficult to make with confidence for the data presented in this study. The ray geometry for radiation emanating from a shallow, vertical strike-slip fault in a spherical layered Earth is such that direct $P$ waves reaching teleseismic stations $\left(\Delta \geqq 40^{\circ}\right)$ depart from the source with small angles $\left(\leqq 28^{\circ}\right)$ relative to the (vertical) dip of the fault plane; accordingly these stations are close to nodes in the $P$-wave radiation pattern (Ben-Menahem et al., 1965). Radiation pattern nodes are relatively unstable with respect to fault-plane geometry; that is, small changes in the fault-plane orientation can lead to large changes in $\mathscr{R}_{\theta \varphi}$.

It is our experience that $P$-wave spectral amplitudes near the computed nodes are only rarely as weak as expected from the $\mathscr{R}_{\theta \varphi}$ calculations. This general result can be indicated by a comparison of the computed value of $\mathscr{R}_{\theta \varphi}$ to $\Omega_{o}$ (Tables 4 and 7 ). There is no general correlation of $\mathscr{R}_{\theta \varphi}$ and $P$-wave spectral amplitudes, despite the fact that $\mathscr{R}_{\theta \varphi}$ 
varies over 2 orders of magnitude. [The expected variation of signal amplitude over the range $35^{\circ} \leqq \Delta \leqq 80^{\circ}$ due to geometrical spreading (Julian and Anderson, 1968) is relatively small and can be ignored for the purpose of this comparison.] The only longperiod $P$ signal that really seems to possess nodal spectral amplitudes is NAT (August 31, 1968). It is also worth noting here that, whereas the long-period spectral amplitudes for this signal are depressed by a factor of 10 relative to other $P$ signals for the Iran event, the short-period spectral amplitudes are not.

Nuttli and Gudaitis (1966) have made similar observations. They point out that the expected nodal behavior of long-period $P$-wave amplitudes is generally confined only to the first half-cycle; the amplitude of the second half-cycle remained relatively large, even near nodes. In that the $\Omega_{o}$ approximation arises from several cycles of the longperiod signal, we would expect that moment determinations based on body waves near point-source nodes would be too large, that is, overcorrected for $\mathscr{R}_{\theta \varphi}$. Accordingly, we have not attempted a moment determination when $\mathscr{R}_{\theta \varphi}$ was less than 0.05 . With this restriction, the rms errors of the moment determinations are relatively small, 18 per cent, 41 per cent and 49 per cent for the $P$-wave moments of the California, Turkey and Iran earthquakes, respectively.

The node in the $S H$ radiation pattern for rays reaching teleseismic distances from a vertical strike-slip source is not so profound. For the earthquakes considered here, the $S H$ waves are more reliable for $M_{o}$ determinations, but the distance range and station azimuth for recording stations are more restricted because of the $S c S$ arrival and $S$ coupled $P L$ waves, respectively (see below). For other source geometries, for example dip-slip motion on a fault plane dipping $45^{\circ}, P$ waves would be near a maximum and the $S H$ waves near a node in the radiation pattern for signals received at teleseismic distances. This is the case for the San Fernando, California, earthquake of February 9, 1971 (Wyss and Hanks, 1972). A reliable moment determination should in general include analysis of both $P$ and $S$ waves.

The correction for geometrical spreading (Julian and Anderson, 1968) is straightforward and has a relatively small error associated with it, provided that $\Delta \geqq 35^{\circ}$ so that the signal is not sensitive to upper mantle structure (Helmberger and Wiggins, 1971). No attempt has been made to remove the crustal transfer function for an individual station since the local crustal structures are generally not well enough known. In the seismic moment determinations, an average correction to the long-period amplitudes for the combined effect of the free surface and crust was made by dividing $\Omega_{o}$ by 2.5 (Ben-Menahem et al., 1965). The error associated with this assumption should be small.

We have made no attempt to extract reflected ( $p P$ or $s S$ ) or multiple arrivals from the direct wave. The theoretical, point-source effect of $p P, s S$, is to degrade the spectral amplitudes by a factor of $\omega=2 \pi / T$ for periods long compared to $2 h / \alpha, \beta$, where $h$ is the depth of the point source and the choice of $\alpha$ or $\beta$ depends on whether the $P$ or $S$ wave is being considered. The applicability of this result for a large shallow earthquake $(r \gg h / 2$, where $h / 2=$ average depth of any point source) that ruptures the surface, however, is not straightforward. We do not think that the predicted effect for periods long compared to 2 or $3 \sec (P)$ and 3 to $5 \sec (S)$ is apparent in the spectra presented.

In the case of the $S$ waves for the Turkey and particularly the Iran events, it was generally necessary to take a sample of 100 to $120 \mathrm{sec}$ to define $f_{o}$ and $\Omega_{o}$ adequately. Almost all $S$ waves analyzed have been at epicentral distances $50^{\circ} \leqq \Delta \leqq 65^{\circ}$ so that the $S c S-S$ time is maximal $\left(\Delta=50^{\circ}, S c S-S \simeq 160 \mathrm{sec} ; \Delta=60^{\circ}, S c S-S \cong 100 \mathrm{sec} ; \Delta=70^{\circ}\right.$, $S c S-S \simeq 60 \mathrm{sec}$ (Richter, 1958)). Most $S$ waves have been chosen at stations $\Delta<60^{\circ}$, but for the few $S$ waves at $\Delta>60^{\circ}$, the necessity for longer sample lengths for the Turkey and Iran earthquakes will include at least part of the $S c S$ phase. Similarly, $\Omega_{o}(P)$ is often 
based on a signal that includes $P c P$. We have made no effort to extract it, realizing that unless phase differences are exactly right, $\Omega_{0}$ should be somewhat overestimated, by no more than a factor of 2 . This error is comparable to that associated with the choice of $\Omega_{o}$.

An additional restriction on the use of $S$ waves at teleseismic distances involves the shear-coupled $P L$ wave. This complicated arrival (Chandler et al., 1968) can be avoided by choosing $S$ waves for which either the back-azimuth is closely parallel to one horizontal component or the $S V$ radiation is close to a node. In this way it is possible to isolate the majority of $S H$ motion. Almost all of the $M_{o}(S)$ determinations have been estimated from $S H$-spectral amplitudes, corrected for the $S H$-wave radiation pattern. In a few cases where the above conditions were not fulfilled, we have taken a vector sum of the two horizontal components, subtracting the $S V$ motion from both. The error associated with the correct identification of the $S H$ motion is probably less than a factor of 2 .

The major error in any moment determination from teleseismic body-wave spectra is associated with $\mathscr{R}_{\theta \varphi}$. The other errors are approximately a factor of 2 or less. With use of both $P$ and $S$ waves, the likely error in a moment determination from teleseismic body-wave spectra, averaged over a large enough number of non-nodal stations, should be no more than a factor of 3 or 4 . Agreement to this accuracy between $M_{o}$ based on body waves and $M_{0}$ based on surface waves is easily obtainable (Wyss, 1970; Wyss and Hanks, 1972).

Moment determination from field data. The error associated with $M_{o}(F)=\mu \bar{u} A$ is mostly related to uncertainties in $\bar{u}$ and $A$. The shear modulus is generally well-known from the $S$-wave velocity in the source region. In either case, (3) or (4), it should be remembered that $\mu$ is to be taken as a "stiffness" measure of the source volume, which should not depend seriously on local (and perhaps severe) variations very close to the fault surface.

The fault length and width (depth) can be estimated from surface rupture and aftershock distribution reasonably well. The fault area $A=L h$ can probably be obtained to a factor of 2 . In the case of the California earthquake, the area is known somewhat better. The largest uncertainty is connected with the choice of $\bar{u}$. In the case of the Parkfield, California, earthquake, the displacement at depth must have been larger than that observed at the surface hours after the event (Aki, 1968; Haskell, 1969), although subsequent creep motion accumulated surface displacement of about one half the amount estimated for greater depth (Smith and Wyss, 1968). A reasonable error that could be associated with the estimate of $\bar{u}$ from surface displacements is a factor of 2 or 3 . The error associated with $M_{o}(F)$ should be no more than a factor of 3 to 5 , an error similar to that expected for $M_{o}(P, S)$.

Fault length determinations. As noted in an earlier section, we expect the determination of $r$ using (5) or (7) to be up to 30 per cent lower than the observed $L / 2$. While this source of error is small relative to others in the source dimension determination (see below), it is also a systematic error. We will reserve comment on it until a summary of all of the source-dimension determinations is discussed.

A consequence of a source moving with a finite velocity is that the radiated energy will be focused in the direction of propagation; $f_{o}$ in the propagation direction will be high compared to $f_{o}$ in the opposite direction. For a source moving uniformly with rupture velocity, $v_{r}$, this azimuth dependence can be predicted from the directivity function of Ben-Menahem (1961). Figure 12 is a plot of $f_{o}(P)$ for the three earthquakes considered against stations azimuths. The strike azimuths of the preferred slip planes are also indicated. $f_{o}(P)$ seems to be most closely related to the strike azimuth (in the sense of the directivity function) in the case of the California earthquake, although the maxima 
minima for $f_{o}(P)$ appear to be shifted $5^{\circ}$ to $10^{\circ}$ counterclockwise with respect to the strike azimuth. The small number and scatter of the data, however, are only suggestive of rupture propagation from southeast to northwest.

The other two earthquakes are not so simple. The Turkey earthquake has maxima in $f_{o}(P)$ at both ends of a line shifted approximately $30^{\circ}$ clockwise to the strike azimuth. The maximum to the southeast is not so well-defined as that to the northwest. In addition, the three points between $180^{\circ}$ and $200^{\circ}$ are hardly consistent for such a narrow azimuth range, but, as noted earlier, $f_{o}(P)$ for BUL is probably overestimated. In the case of the Iran earthquake, $f_{0}(P)$ appears to have a maximum at northern azimuths but the lack of data to the south precludes an estimate of its relative strength.
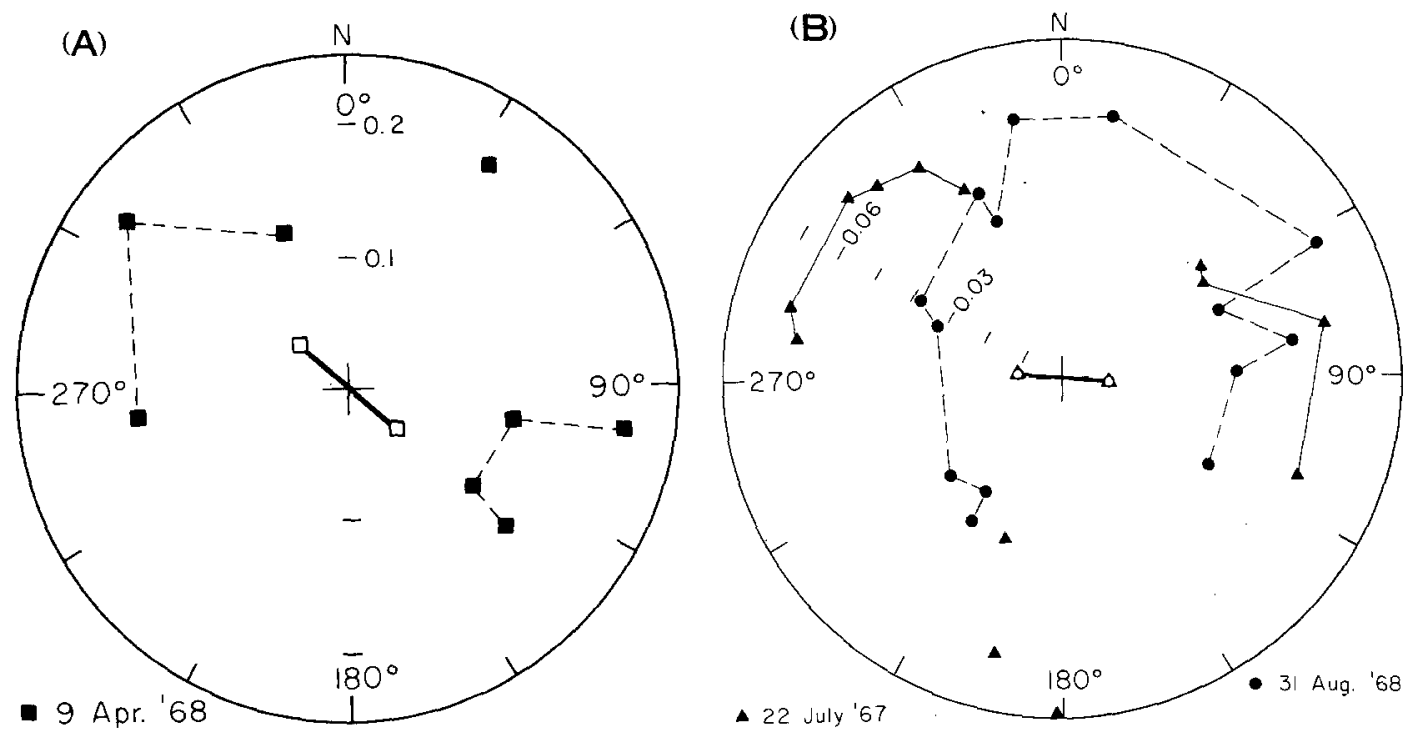

FIG. 12. Azimuth plots of $f_{o}(P)$. Solid lines connecting open symbols at the center of the illustrations indicate the fault trace of preferred fault plane. (a) California earthquake, (b) Turkey and Iran earthquakes.

We have not attempted to interpret the individual spectra in terms of the directivity function since proper identification of the minima in this function would necessitate more detailed knowledge of the crustal transfer function and a better instrument response in the 3- to 6-sec range than were available for this study. Another complicating factor is that the signals from which the $f_{o}(P)$ determinations were obtained traveled in a direction more nearly normal to the planes in Figure 12 rather than in them.

In a previous section, we noted that the choice of $f_{o}$ for any given spectrum could be made with an uncertainty of 1.5. An azimuth plot of $f_{o}(P)$ suggests that a comparable deviation from the mean value is introduced by propagation effects. Averaging over a sufficient number of stations should decrease the latter error, and we feel that $\bar{f}_{0}(P)$ (and $\tilde{r}$ ) can be determined to a factor of 1.5 .

One further point with respect to the determination of $f_{0}$ should be noted. In approximating spectral data by an $\Omega_{o}-f_{0}$ fit, $f_{o}$ in general will be overestimated if $\Omega_{o}$ is underestimated, and conversely; this is merely a consequence of the geometry of the intersecting asymptotes (Figure 1). In the case of NAT P (August 31, 1968), the long-period data are plainly suppressed relative to the short-period data (Figure 10); thus $\Omega_{o}$ is underestimated and the choice of $f_{o}$ is definitely high relative to $f_{0}$ for other $P$-wave spectra for this event (Table 7). For this reason $f_{a}(P)$ NAT has not been included in the 
$\bar{r}(P)$ determination for the Iran earthquake. Similar remarks are applicable to the $S$ wave from the Iran earthquake at $\mathrm{HKC}(\mathrm{EW})$, and the $P$ wave from the Turkey earthquake at BUL, although the effect is not so dramatic.

Summary of seismic moment and source-dimension estimates. Generally, determinations of the parameters seismic moment and source dimension agree well with estimates of the same quantities obtained from the field data (Tables 3, 6 and 9). For the California earthquake, we have obtained an average seismic moment from $P$-wave spectra, $\bar{M}_{o}(P)=10 \times 10^{25}$ dyne-cm, an average seismic moment from $S$-wave spectra, $\bar{M}_{o}(S)=$ $6.6 \times 10^{25}$ dyne-cm, and a seismic moment from field data, $M_{o}(F)=3.6-4.9 \times 10^{25}$ dyne-cm, depending on the choice of fault length. With respect to the estimated errors, the agreement is considered good. The agreement is also good for the fault length determination: $\bar{r}(P)=14 \mathrm{~km}, \bar{r}(S)=23 \mathrm{~km}, L / 2(F)=17 \mathrm{~km}$. If the fault length defined by the aftershock sequence, $45 \mathrm{~km}$, is correct, $\vec{r}(P)$ is low by a factor of 1.6 .

For the Turkey earthquake, we have obtained $\bar{M}_{o}(P)=9.1 \times 10^{26}$ dyne-cm, $\bar{M}_{o}(S)=$ $8.5 \times 10^{26}$ dyne-cm, and $M_{o}(F)=7.4 \times 10^{26}$ dyne-cm. The agreement here is excellent, much better than the error estimates would lead us to expect. The agreement in fault length determination is also excellent: $\bar{r}(P)=39 \mathrm{~km}, \bar{r}(S)=48 \mathrm{~km}$, and $L / 2(F)=40 \mathrm{~km}$. For the Iran earthquake, we have obtained $\bar{M}_{o}(P)=4.8 \times 10^{26} \mathrm{dyne}-\mathrm{cm}, \bar{M}_{o}(S)=$ $8.6 \times 10^{26}$ dyne-cm, and $M_{o}(F)=18 \times 10^{26}$ dyne-cm. The spectral moment determinations for this event are lower than the field moment by a factor of 2 to 4 . Fault length determinations for this earthquake are in relatively good agreement: $\bar{r}(P)=51 \mathrm{~km}$, $\bar{r}(S)=48 \mathrm{~km}$, and $L / 2(F)=40 \mathrm{~km}$. A summary of $\bar{M}_{\mathrm{o}}$ and $\bar{r}(P, S$, and $F$ data weighted equally) for the three earthquakes appears in Table 10 .

TABLE 10

Summary of Source Parameter Estimates

\begin{tabular}{lcccccc} 
Earthquake & $\begin{array}{c}\bar{M}_{o}^{*} \\
\left(\times 10^{25} \mathrm{dyne- \textrm {cm } )}\right.\end{array}$ & $\begin{array}{c}\bar{r}^{*} \\
(\mathrm{~km})\end{array}$ & $\begin{array}{c}E_{S}(S) \\
\left(\times 10^{20} \mathrm{ergs}\right)\end{array}$ & $\begin{array}{c}E_{G-R} \\
\left(\times 10^{20} \mathrm{ergs}\right)\end{array}$ & $\begin{array}{c}\Delta o\left(M_{o}, r\right) \\
(\text { bars })\end{array}$ & $\begin{array}{c}\Delta \sigma\left(u_{\max }, h\right) \\
(\mathrm{bars})\end{array}$ \\
\hline California & 6.7 & 18 & 1 & $10+$ & 5 & 6 \\
Turkey & 83.0 & 42 & 35 & $300+$ & 5 & 16 \\
Iran & 100.0 & 46 & 26 & $400+$ & 5 & 37 \\
\hline
\end{tabular}

\footnotetext{
* $\bar{P}, \bar{S}$, and $F$ results weighted equally

$\dagger E_{G^{-R}}=9.9+1.9 M_{L}-0.024 M_{L}^{2}$

$\ddagger E_{\mathrm{G}^{-} R}=11.8+1.5 \mathrm{M}$
}

Several additional points are worth making in light of the generally good agreement between the several estimates for the seismic moment and source dimension. First, $\bar{M}_{o}(P)$ and $\bar{M}_{o}(S)$ agree with each other at least as well as either agrees with $M_{o}(F)$ for the three earthquakes considered. This observation suggests that the errors associated with $M_{o}(F)$ may be somewhat larger than the errors associated with $\bar{M}_{o}(P)$ and $\bar{M}_{o}(S)$; we might suspect this to be the case if the error in $\mathscr{R}_{\theta \varphi}$ is reduced by averaging over a large enough number of stations. With respect to $\bar{M}_{o}(P)$ and $\bar{M}_{o}(S), M_{o}(F)$ for the Iran earthquake appears to be overestimated by a factor of 2 to 4 . On the other hand, $M_{o}(F)$ for the California earthquake appears to be underestimated by a factor of 2 or 3 . We feel that these errors are acceptable in any case and that the seismic moment for these events can be reliably recovered from teleseismic body-wave spectra.

Secondly, $P$-wave spectra appear to be as reliable as $S$-wave spectra in recovering $r$, 
as well as $M_{o}$, provided that (7) is used to estimate $r$ from $f_{o}(P)$. The relations of Kasahara (1957) and Berckhemer and Jacob (1968) between $r$ and $f_{o}(P)$ do not give such good agreement with the observed fault length. The advantages of using $P$ waves are several; they are uncontaminated by earlier arrivals, and they are less sensitive to anelastic attenuation. In addition, the spectral shift of $f_{0}(P)$ from $f_{0}(S)$ may make the $P$ wave preferable for the analysis, depending on the recording instrumentation. It should be remembered, however, that (7) is only a plausible assumption; this relation seems to work, within the uncertainties of the analysis, for the three earthquakes considered here and for the San Fernando earthquake as well (Wyss and Hanks, 1972). Kisslinger et al. (1971) have reported that they have been able to recover consistent source dimensions for smaller earthquakes using $S$ waves and (5) or $P$ waves and (7). It should be noted, as has Savage (1972), that our assumption and observational finding (in an average sense) that $f_{o}(P) / f_{0}(S) \simeq \alpha / \beta$ cannot be rationalized in terms of the directivity function for reasonable values of rupture velocity.

Thirdly, the anticipated systematic error in the source-dimension determination arising from rectangular source geometry is not apparent in the comparison of the sourcedimension determinations. The disagreement should have been more obvious for the Turkey and Iran earthquakes ( $\delta \simeq \frac{1}{2}$ ) than for the California earthquake $\left(\delta \simeq \frac{2}{3}\right)$. We might conclude that $h$ is somewhat greater, perhaps to 25 to $30 \mathrm{~km}$, for the former events. This, however, would imply that $M_{o}(F)$ for these two events would have been underestimated by approximately 50 per cent; in the case of the Iran earthquake, $M_{0}(F)$ is already high by a factor of 2 to 4 . In any case, the anticipated error is not serious. The geometry of faulting of these events did not provide a crucial test for the rectangular scaling.

Finally, similar analyses of earthquakes using WWSSN body-wave data will be useful for only a limited range of magnitudes, since the foregoing analysis and interpretation are dependent on reliable spectral data over a relatively wide frequency range. With respect to the long-period instrument operating at a gain of $1500, P$ waves for the California earthquake were occasionally unresolvable, whereas $S$ waves for the Turkey and Iran earthquakes were often off-scale. As such, it will not be generally possible to obtain reliable long-period amplitudes for both the $P$ and $S$ waves for events much smaller than the California earthquake or much larger than the Turkey and Iran earthquakes. An additional complication is that $f_{o}$ can be expected to increase with decreasing magnitude. Thus, for earthquakes smaller than the California earthquake, $f_{o}(P)$ can be expected to move into the gap in the combined short- and long-period WWSSN response while $f_{o}(S)$ for events much larger than the Turkey or Iran earthquakes will be too far removed from the long-period peak response to be defined adequately.

For shallow earthquakes, these two phenomena effectively limit similar analyses using teleseismic WWSSN body-wave data to events for which $6.0 \leqq M \lesssim 7.5$. Taking advantage of the spectral shift offers additional leeway; that is, $P$ waves are preferable in both respects for the larger earthquakes while $S$ waves are similarly preferable for events near the lower magnitude limit. The preference for $P$ or $S$ waves, however, is also controlled by the fault-plane geometry.

This magnitude restriction applies only to the use of body waves from shallow earthquakes at teleseismic WWSSN stations. Surface-wave spectra have been used with much success for source parameter determination of larger shallow events, and WWSSN bodywave spectra at small epicentral distances should be useful for the smaller and deeper events, at the expense of a restricted sampling of the focal sphere. In general, however, there is a clear need for higher gain, broader-band seismic systems for similar analyses of $M \leqslant 6$ events. 
It should be emphasized that the results described above are only sufficient to describe the long-time, average displacement on an equivalent circular fault surface. No attempt has been made to describe details of the faulting motion, which can only be extracted from the high-frequency $\left(f>f_{o}\right)$ spectral amplitudes. The practical difficulties in obtaining reliable high-frequency spectral amplitudes and the theoretical difficulties in relating them to details of the fault motion are beyond the scope of this paper. The major function of the short-period spectral amplitude data has been to facilitate the $f_{o}$ determination.

\section{Estimate of RADiated ENergy}

The energy radiated, $E_{s}$, in a particular signal can be expressed in terms of its spectral amplitudes

$$
E_{s} \propto \frac{1}{2 \pi} \int_{-\infty}^{\infty}|\Omega(\omega) \cdot \omega|^{2} d \omega
$$

This result follows from a straightforward application of Parseval's Theorem to a volume integration of the kinetic energy density (for example, $\mathrm{Wu}, 1966$ ). When $\Omega(\omega)$ is given by the Brune spectra (Figure 1; note that the knee in the spectrum has been approximated by the intersection of the asymptotes), (16) takes a particularly convenient form

$$
E_{s} \propto k \Omega_{0}{ }^{2} f_{0}{ }^{3} .
$$

This approximation, while consistent with our spectral interpretations, overestimates the exact evaluation of the energy integral for the Brune spectrum $(\varepsilon=1)$ by approximately a factor of 2 ; we have accounted for it in (18). The important aspect of (17) is that $E_{s}$ can be expressed in terms of quantities which depend only on the physical properties of the source and not on the propagation path nor source geometry.

We have used the following relation in the determination of the radiated energy

$$
E_{s}(P, S)=\frac{I(P, S)}{2} \rho(\alpha, \beta) R^{2}(2 \pi)^{2} \frac{\Omega_{0}{ }^{2}(P, S)}{\mathscr{R}_{\theta \varphi}{ }^{2}(P, S)} f_{0}{ }^{3}(P, S)\left(\frac{1}{3}+\frac{1}{2 \gamma-3}\right), \gamma>1.5 .
$$

The choice of $P$ or $S$ and $\alpha$ or $\beta$ depends on whether $E_{s}$ is to be determined from the $P$ or $S$ phase. $I(P, S)$ is the spatial integration of the $P_{-}, S$-wave radiation pattern about the source. It has been divided by 2 since the spatial integrations are for a whole space. $I(P)=4 \pi / 15$, and $I(S)=24 \pi / 15(\mathrm{Wu}, 1966)$. The value chosen for $I(S)$ will include both $S V$ and $S H$ motion in the radiated energy estimate, although generally $\Omega_{o}(S)$ is determined from only one horizontal component. As noted earlier, however, this estimate is associated with only a minor error. It is presumed that $\Omega_{o}$ and $f_{o}$ are corrected for all propagation effects other than geometrical spreading and radiation pattern. Then the quantity $\left(\Omega_{o} R / \mathscr{R}_{\theta \varphi}\right)^{2}$ in (18) can be replaced by $\left(M_{o} / 4 \pi \rho \beta^{3}\right)^{2}$. The factor of $(2 \pi)^{2}$ arises from conversion from circular frequency, and the quantity $\frac{1}{3}+1 / 2 \gamma-3$ arises from the arithmetic of the frequency integration. $\gamma$ is the exponent of high-frequency decay for $f>f_{o}$, should it be different from $2 ; \gamma$ must be greater than 1.5 for (18) to converge.

We can construct a ratio of $E_{\mathrm{s}}(P) / E_{s}(S)$ from (18), assuming that $\gamma$ is constant for both the $P$ - and $S$-wave spectra

$$
\frac{E_{s}(P)}{E_{s}(S)}=\frac{I(P) \alpha \Omega_{0}{ }^{2}(P) \mathscr{R}_{\theta \phi}^{2}(S) f_{0}{ }^{3}(P)}{I(S) \beta \Omega_{0}{ }^{2}(S) \mathscr{R} \mathscr{R}_{\theta \phi}(P) f_{0}{ }^{3}(S)}
$$


Assuming that $\Omega_{o}{ }^{2}(P) \mathscr{R}_{\theta \phi}{ }^{2}(S) / \Omega_{o}{ }^{2}(S) \mathscr{R}_{\theta \phi}^{2}(P)=\beta^{3} / \alpha^{3}$ and $f_{o}(P) / f_{o}(S)=\alpha / \beta$ (Figure 1), we have, using the values for $I(P)$ and $I(S)$ given above.

$$
\frac{E_{s}(P)}{E_{s}(S)}=\frac{1}{6} \frac{\beta^{2}}{\alpha^{2}}=\frac{1}{18}, \frac{\alpha}{\beta}=\sqrt{ } 3 .
$$

Thus, $E_{s}(P)$ is less than $E_{s}(S)$ by a factor of approximately 20 , and it is no large error to neglect $E_{s}(P)$.

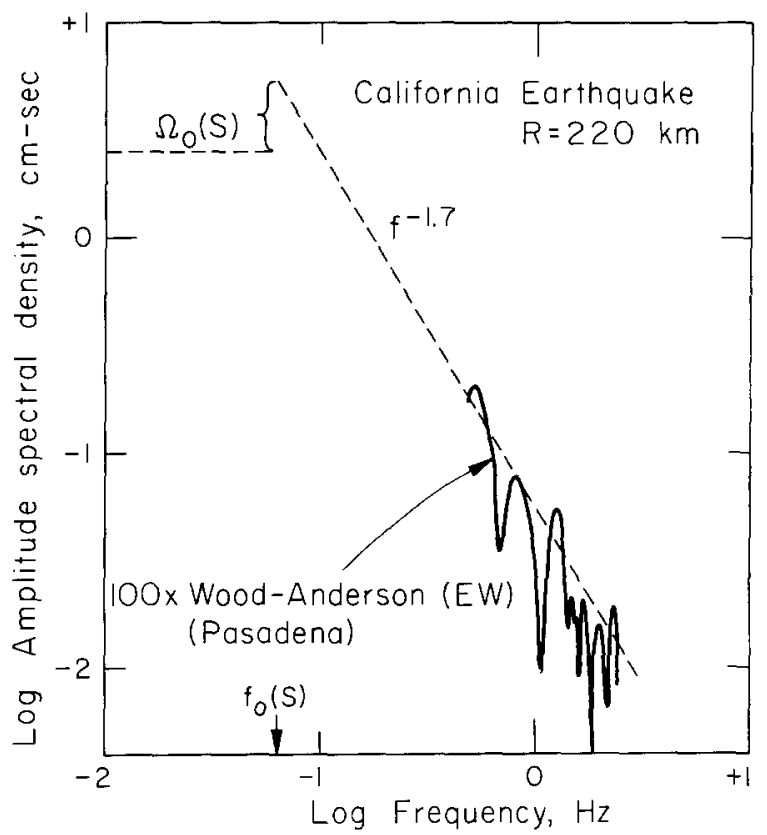

Fic, 13. S-wave spectrum of the California earthquake at Pasadena. Solid line is spectral data from Wood-Anderson record $(100 \times)$.

Figure 13 is a composite spectrum at Pasadena for the California earthquake. The short-period spectral data have been obtained from low-gain $(100 \times)$ Wood-Anderson instruments at Pasadena. The high-frequency $S$-wave data obtained at Pasadena are a useful consistency check on the same data obtained at teleseismic distances. These data have been extrapolated to $f_{o}(S)$, which can be taken as an average of the teleseismic observations or computed from the fault length. The horizontal dashed line is a representation of $\Omega_{o} / \mathscr{R}_{\theta \varphi}$, computed from $M_{o}$. The amount of mismatch is certainly acceptable, given the errors in the moment and source dimension determinations and the hazards of extrapolating short-period data. From Figure 13 and (18), we calculate that $E_{s}(S)$ is $1.7 \times 10^{20}$ ergs. Similar calculations $(\gamma=1.7)$ based on teleseismic $\Omega_{o}(S)-f_{o}(S)$ determinations yield similar results (Table 2 ). This is not surprising since the only variables in the energy estimates are $\Omega_{o}$ and $f_{o}$, and these quantities are consistent from station to station when corrected for propagation effects and source geometry.

Using $\Omega_{o}(S), f_{o}(S)$, and $\gamma=1.7$, we have determined $E_{s}(S)$ for the $S$ waves of the Turkey and Iran earthquakes. Individual estimates are given in Tables 5 and 8 , respectively, and average $E_{s}(S)$ determinations for these three earthquakes are given in Table 10, together with the radiated energy estimate, determined from the indicated energymagnitude relation, $E_{G-R}$. This quantity is larger than $E_{s}(S)$ by a factor of 10 for these earthquakes. On the other hand, $E_{s}(S)$ is only a lower-bound estimate for the radiated 
energy, since we have assumed complete effective stress drop. In the case of the San Fernando earthquake, $E_{s}(S)$ and $E_{G-R}$ agree within a factor of 2 (Wyss and Hanks, 1972).

Implicit in (18) and its analog with $\varepsilon$ arbitrary is that, having determined (or assumed) $\Omega_{o}, f_{o}$, and $\varepsilon, E_{s}(S, P)$ is not an independent quantity; the assumption of $\varepsilon=1$ provides a lower-bound estimate. For the very reason that $E_{s}$ is not an independent quantity in a general dislocation model of the seismic source, (18) provides a particularly useful method of determining radiated energies. Even so, we do not minimize the difficulties of determining seismically radiated energy; within the context of (18), the major uncertainty is associated with determination of $\varepsilon$ from observed spectra.

\section{STRESS DROPS}

Stress drops for these earthquakes have been computed on the basis of

$$
\Delta \sigma\left(M_{0}, r\right)=\frac{7}{16} \frac{M_{o}}{r^{3}} \quad \begin{aligned}
& \text { (corrected from Brune, } 1970, \\
& \text { by Brune, 1971) }
\end{aligned}
$$

and

$$
\Delta \sigma\left(u_{\max }, h\right)=\frac{1}{2} \frac{u_{\max }}{h} \mu . \quad \text { (Knopoff, 1958) }
$$

The results are given in Table 10 . Within the accuracy of the $\Delta \sigma$ determinations, wo can consider these earthquakes to have stress drops of the order of 10 bars. Similar $\Delta \sigma$ values have been obtained for the Parkfield (1966), California, earthquake (Scholz et al., 1969) and for the San Fernando (1971), California, earthquake (Wyss and Hanks, 1972). Since the stress drop of an earthquake must represent the minimum tectonic stress operative to cause the event, as well as a minimum estimate of the material strength in the vicinity of the source, it follows that if the material strength near the rupture surface was much greater than 10 bars, these three earthquakes, as well as the Parkfield and San Fernando events, did little to relieve the accumulation of tectonic strain that gave rise to them.

\section{Conclusions}

The source parameters seismic moment and source dimension, as estimated from teleseismic body-wave spectra interpreted following Brune (1970), agree well with the same parameters obtained from field data for three large shallow earthquakes generating predominantly strike-slip motion on a nearly vertical fault plane. The Brune (1970) seismic-source model is well-calibrated for determination of these source parameters for the earthquakes considered. A minimum estimate for the radiated energy can be conveniently expressed in terms of the spectral parameters $\Omega_{o}$ and $f_{o}$. These estimates are low by a factor of 10 with respect to estimates obtained from energy-magnitude relations for the three earthquakes considered. Stress drops for these events are of the order of 10 bars.

\section{ACKNOWLEDGMENTS}

This work was supported by NSF Grant Ga-12868 (Earthquake Mechanisms), by the Advanced Research Projects Agency under the Air Force Office of Scientific Research Contracts AF 44620-69-C0067 and AF 19628-71-C-0245, and by the U.S. Geological Survey Contract 14-08-0001-12289 under ARPA Order No. 1684. John Kuo, Keith McCamy, Otto Nuttli, and Lynn Sykes read the manuscript and provided several pertinent comments. We benefited from discussions with James Savage concerning the directivity function. Peter Molnar and Mihailo Trifunac pointed out the error associated with the asymptotic approximation in the radiated energy integral. 


\section{REFERENCES}

Aki, K. (1966). Generation and propagation of $G$-waves from the Niigata earthquake of June 16, 1964. Part 2. Estimation of earthquake moment, released energy, and stress-strain drop from the $G$-wave spectrum, Bull. Earthquake Res. Inst., Tokyo Univ. 44, 73-88.

Aki, K. (1967). Scaling law of seismic spectrum, J. Geophys. Res. 72, 1217-1231.

Aki, K. (1968). Seismic displacements near a fault, J. Geophys. Res. 73, 5359-5376.

Allen, C. R., A. Grantz, J. N. Brune, M. M. Clark, R. V. Sharp, T. G. Theodore, E. W. Wolfe, and M. Wyss (1968). The Borrego Mountain, California, earthquake of 9 April 1968: A preliminary report, Bull. Seism. Soc. Am. 58, 1183-1186.

Allen, C. R. and J. M. Nordquist (1971). Borrego Mountain earthquake: Foreshock, main shock, and larger aftershocks, U.S. Geol. Survey Professional Paper (in press).

Ambraseys, N. N. and J. S. Tchalenko (1969). The Dasht-e-Bayāz (Iran) earthquake of August 31, 1968: A field report, Bull. Seism. Soc. Am. 59, 1751-1792.

Ambraseys, N. N. and A. Zatopek (1969). The Mudurnu Valley, West Anatolia, Turkey, earthquake of 22 July 1967, Bull. Seism. Soc. Am. 59, 521-589.

Archambeau, C. B. (1964). Elastodynamic source theory, Ph.D. Thesis, California Institute of Technology.

Archambeau, C. B. (1968). General theory of elastodynamic source fields, Rev. Geophys. 6, 241-287.

Ben-Menahem, A. (1961). Radiation of seismic surface waves from finite moving sources, Bull. Seism. Soc. Am. 51, 401-435.

Ben-Menahem, A. and D. G. Harkrider (1964). Radiation patterns of seismic surface waves from buried dipolar point sources in a flat stratified earth, J. Geophys. Res. 69, 2605-2620.

Ben-Menahem, A., S. W. Smith, and T. L. Teng (1965). A procedure for source studies from spectrums of long-period seismic waves, Bull. Seism. Soc. Am. 55, 203-235.

Berckhemer, H. and K. H. Jacob (1968). Investigation of the dynamical process in earthquake foci by analyzing the pulse shape of body waves, Final Sci. Rep. AF 61(052)-801, Air Force Cambridge Research Laboratories.

Brune, J. N. (1970). Tectonic stress and the spectra of seismic shear waves from earthquakes, $J$. Geophys. Res. 75, 4997-5009.

Brune, J. N. (1971). Correction (to Brune (1970)), J. Geophys. Res. 76, 5002.

Brune, J. N. and C. R. Allen (1967). A low stress-drop, low magnitude earthquake with surface faulting: The Imperial, California, earthquake of March 4, 1966, Bull. Seism. Soc. Am. 57, 501-514.

Chander, R., L. E. Alsop, and J. Oliver (1968). On the synthesis of shear-coupled PL waves, Bull. Seism. Soc. Am. 58, 1849-1877.

Crampin, S. (1969). Aftershocks of the Dasht-e-Bayāz, Iran, earthquake of August, 1968, Bull. Seism. Soc. Am. 59, 1823/1841.

Hamilton, R. M. (1971). Aftershocks of the Borrego Mountain earthquake, April 12 to June 12, 1968, U.S. Geol. Survey Professional Paper (in press).

Haskell, N. (1964). Total energy and energy spectral density of elastic wave radiation from propagating faults, Bull. Seism. Soc. Am. 54, 1811-1841.

Haskell, N. (1969). Elastic displacements in the near-field of a propagating fault, Bull. Seism. Soc. Am. $59,865-908$.

Helmberger, D. V. and R. A. Wiggins (1971). Upper mantle structure of mid-western United States, J. Geophys. Res. 76, 3229-3245.

Jeffreys, H. (1931). On the cause of oscillatory movement in seismograms, Mon. Notic. Roy. Astron. Soc., Geophys. Suppl. 2, 407-416.

Julian, B. R. and D. L. Anderson (1968). Travel times, apparent velocities, and amplitudes of body waves, Bull. Seism. Soc. Am. 58, 339-366.

Kasahara, K. (1957). The nature of seismic origins as inferred from seismological and geodetic observations, Bull. Earthquake Res. Inst., Tokyo Univ. 35, 473-530.

Keilis-Borok, V. I. (1960). Investigation of the mechanism of earthquakes, Sov. Res. Geophys. (English transl.) 4,29 .

Kisslinger, C., R. Agrawal, and R. Rodriguez (1971). Properties of recent earthquakes in the New Madrid seismic zone, Trans. Am. Geophys. Union 52, 278.

Knopoff, L. (1958). Energy release in earthquakes, Geophys. J. 1, 44-52.

Niazi, M. (1969). Source dynamics of the Dasht-e-Bayāz earthquake of August 31, 1968, Bull. Seism. Soc. Am. 59, 1843-1861.

Nuttli, O. W. and V. V. Gudaitis (1966). On the amplittdes of long period $P$ waves (abstract), Earthquake Notes 37, (4) 24. 
Richter, C. F. (1958). Elementary Seismology, W. H. Freeman, San Francisco, 768 pp.

Savage, J. C. (1972). The relation of corner frequency to fault dimensions, J. Geophys. Res. (in press).

Scholz, C. H. M. Wyss, and S. W. Smith (1969), Seismic and aseismic slip on the San Andreas fault, J. Geophys. Res. 74, 2049-2069.

Sharpe, J. A. (1942). The production of elastic waves by explosive pressures, 1, Theory and empirical field observations, Geophysics 7, 144-154.

Smith, S. W. and M. Wyss (1968). Displacement on the San Andreas fault initiated by the 1966 Parkfield earthquake, Bull. Seism. Soc. Am. 58, 1955-1974.

Wu, F. T. (1966). Lower limit of the total energy of earthquakes and partitioning of energy among seismic waves, Ph.D. Thesis, California Institute of Technology.

Wyss, M. (1970). Stress estimates of South American shallow and deep earthquakes, J. Geophys. Res. 75, $1529-1544$.

Wyss, M. and T. C. Hanks (1972). The source parameters of the San Fernando earthquake inferred from teleseismic body waves, Bull. Seism. Soc. Am. 62, 591-602.

Wyss, M., T. C. Hanks, and R. C. Liebermann (1971). Comparison of $P$-wave spectra of underground explosions and earthquakes, J. Geophys. Res. 76, 2715-2729.

SEISMOLOGICAL LABORATORY

California Institute of Technology

Pasadena, California 91109 (T.C.H)

Contribution No. 2051, Division of

Geological and Planetary Sciences

Manuscript received August 9, 1971
Lamont-Doherty Geological Observatory

Columbia University

Palisades, New York 10964 (M.W.)

Contribution No. 1756 